\title{
Tropical Indian Ocean and ENSO relationships in a changed climate
}

\author{
Marathe Shamal,", Pascal Terray², Karumuri Ashok ${ }^{3}$ \\ ${ }^{1}$ Centre for Climate Change Research, Indian Institute of Tropical Meteorology, Pune, India. \\ ${ }^{2}$ CNRS - IRD - MNHN, LOCEAN Laboratory, Sorbonne Universités (UPMC, Univ Paris 06), 4 Place \\ Jussieu,75005 Paris, France. \\ ${ }^{3}$ Centre for Earth, Ocean and Atmospheric Sciences, University of Hyderabad, Hyderabad, India.
}

*Corresponding Author's address:

Dr.ShamalMarathe

Centre for Climate Change Research,

Indian Institute of Tropical Meteorology, Pune-411008.

Phone: 91-90-1167-8048

e-mail: shamal.marathe@ tropmet.res.in,27shamal.m@gmail.com

Keywords: ENSO, IOD, IOBM, teleconnections, CMIP5, lead correlations 


\section{Abstract}

2 We explore the current (1958-2005 period) and near future (2006-2050 period) teleconnections between El Niño

3 Southern Oscillation (ENSO), Indian Ocean Basin Mode (IOBM), and Indian Ocean Dipole (IOD) as simulated in

4 historical and Representative Concentration Pathway (RCP8.5) simulations of 32 coupled models that participated in

5 the phase five of Coupled Model Intercomparison Project (CMIP5). A set of 16 CMIP5 models out of 32 models,

6 which perform best to simulate tropical climate variability in recent decades, is first selected using a robust method

7 based on the Empirical Orthogonal Function analysis, for detailed analysis.

8 Most of these models show modest capability in reproducing the seasonal cycle of ENSO types in the current period.

9 Further, amplitude of Indian Ocean (IO) modes is overestimated by the 16 models along with large inter-model

10 spread. Based on these results, a subset of 9 models is formed, which simulate a realistic seasonal phase-locking of

11 ENSO for a robust assessment of future teleconnections.

12 No significant change in El Niño amplitude is detected in near future. However the IOBM is projected to be weaker

13 during late spring and early summer. The IOD is projected to be stronger during boreal summer in the future

14 relative to the current period. We also investigate if there are any changes from historical to RCP 8.5 simulations in

15 the strength of the IO negative feedback on ENSO with a multiple linear regression approach. The IO negative

16 feedback strengthens significantly in the RCP8.5 scenario due to the increasing role of IOBM in speeding the

17 transition from El Niño to La Niña, despite its reduction of amplitude, In contrast, IOD loses its predictive value in

18 the future projections. 


\section{Introduction}

21 The ability of Coupled Model Intercomparison Project (CMIP5) models (Taylor et al. 2012) to simulate the El Niño

22 Southern Oscillation (ENSO), Indian Ocean Dipole (IOD) and Indian Ocean Basin Mode (IOBM) phenomena and 23 inter-relationships among them has been well documented in past studies (Bellenger et al. 2014; Chu et al. 2014; Du et al. 2013; Jha et al. 2014; Weare et al. 2013; Zhang et al. 2014; Xie et al. 2016; Saji 2018; Cai et al. 2019; Wang 2019). A positive IOD pattern, with warming in the western Indian Ocean (IO) and cooling in the eastern IO emerges during boreal summer and peak during the boreal fall of the El Niño developing year (Wang 2019). During the following boreal winter, which corresponds to the peak of El Niño, the cold anomalies in the eastern IO disappear and a basin-wide warming (e.g. IOBM) emerges during the next boreal spring, and persists in boreal summer (Xie et al. 2016).

Several previous studies have suggested that ENSO may act as a trigger for some IOD events (e.g. Gualdi et al. 2003; Shinoda et al. 2004) and is a significant IOD predictor (Zhao et al. 2019). However, many IOD events have occurred without a co-occurring El Niño (Saji2018). Further, several positive IOD events have co-occurred with La Niñas (e.g. Ashok et al. 2003; Cai et al. 2009). Jourdain et al. (2016), Wang et al. (2019) and Cai et al. (2019) have further confirmed that the lead-lag relationships between IOD and ENSO are consistent with two-way interactions between them. Sensitivity coupled experiments have also demonstrated that IOD exists without ENSO in the Pacific, and is thus an intrinsic mode of Tropical Indian Ocean (TIO) variability (Fischer et al. 2005; Behera et al. 2006; Sun et al. 2015; Cretat et al. 2017, 2018). Yang et al. (2015) conducted a 10-member coupled simulation and distinguished the development of IOD by two factors viz., ENSO forcing and internal variability. The "internal" IOD decays after October, however ENSO-forced IOD further grows into IOBM (Hong et al. 2010), adding complexity in understanding the relationships between the three climate modes. Interestingly, there is also a decadal variability in the relationship between IOD and ENSO, and there are multiple decades when the IOD-ENSO association is significantly weaker (Ashok et al. 2003; Krishnaswamy et al. 2014; Ham et al. 2017).

While the IOBM may be considered as the IO response to ENSO through the atmospheric bridge (Klein et al. 1999; Alexander et al. 2002; Xie et al. 2016), it may feedback on ENSO, and hastens the transitions from El Niño to La Nina events in the Tropical Pacific (TP; Kug and Kang 2006; Ohba and Ueda 2007; Terray et al. 2016; Xie et al. 2016). Interestingly, this ENSO-induced basin-wide warming in the TIO has more prominent impacts in recent decades, possibly due to global warming (Zheng et al. 2011; Boschat et al. 2012;Ashok et al. 2014, Hu et al. 2014; Tao et al. 2015). Dayan et al. (2014) suggest that the influence of IO Sea Surface Temperature Anomaly (SSTA) on ENSO is due to the IOBM rather than the IOD. However, Hong et al. (2010) have shown that the IOBM is much stronger when El Niño and IOD co-occur during the preceding year. In addition, Izumo et al. (2010, 2014) demonstrate that the negative phase of the IOD is an efficient statistical predictor of El Niño 14 months before its peak According to Jourdain et al. (2016), almost all CMIP5 models establish a significant relationship between IOD and the following year's (i.e., 14 months later) ENSO, but the physical mechanisms responsible of this lead relationship are still elusive. 
The tropical mean climate will undergo a significant change under global warming (e.g., Liu et al. 2005; Vecchi et al. 2008; Collins et al. 2010), especially in the western Pacific (Weller et al. 2016), and western IO (Roxy et al. 2014; Cowan et al. 2015), which are key-regions for the tropical IO and ENSO interactions. Cai et al. (2009, 2014), using CMIPmodels, have shown that, under greenhouse warming, the equatorial IO is evolving towards climatologically stronger west-minus-east temperature gradients and easterly winds, and is more susceptible to producing more frequent extreme positive IOD events (Cai et al. 2014). However, this emerging picture is largely contributed by coupled models, which already simulate excessive IOD variability in the historical period (Li et al.

62 2016). On the other hand, several other papers (e.g. Chu et al. 2014, Zheng et al. 2013) based on CMIP5 future

63 projections reported that interannual variance of the IOD mode remains largely unchanged under global warming,

64 which suggest that this topic needs further analysis. Based on historical simulations and future climate projections of 65 CMIP5 models, Tao et al. (2015) also suggest that the ENSO-IOBM relationship would enhance in the future.

66 Previous studies have mainly focused on the relationships between IOD, IOBM and ENSO during their respective 67 developing and peak phases. A notable exception is Jourdain et al. (2016), which showed that the delayed IOD68 ENSO relationship as simulated in CMIP5 models is in good agreement with observations. In contrast, how state-of69 the-art CGCMs simulate the lead-and-lag relationships between these three modes of variability, and how these 70 significant lead-and-lag relationships, which play a seminal role in seasonal predictability in the tropics (Luo et al. 71 2010, Zhao et al. 2019), will change in the future, are less known.

72 Given the above background, the present study intends to document the current (e.g. 1958-2005 period) and near 73 future (e.g. 2006-2050 period) statistics of teleconnections and lead-lag relationships between ENSO, IOBM and 74 IOD as simulated by 32 CMIP5 coupled models with the help of a robust selection of CMIP5 modelsbased on 75 Empirical Orthogonal Function (EOF) analysis..

76 This paper is organized as follows. Section 2 provides a description of datasetsand statistical methods we used. In 77 the section 3, we document how the CMIP5 models simulate the annual mean SST and variance and what are their 78 projected changes. In section 4, we concentrate on the fidelity of the CMIP5 models in representing the observed 79 Tropical Indo-Pacific(TIP) variability during recent decades. In sections 5 and 6, we examine the monthly standard 80 deviations (SD) of Niño3, EMI, IOBM and IOD indices for the current period, and those for the near future. In 81 sections 7 and 8, we analyse changes in lead-lag correlations between ENSO, IOD and IOBM and in the negative 82 feedback on ENSO. A summary is presented in the final section.

\section{2. Data and Methodology}

\section{$84 \quad$ 2.a Simulations, observations and climate indices}

85 Various simulations from the 32 CMIP5 models have been utilized in this study (Taylor et al. 2012): 

forcing reaches a level of about $8.5 \mathrm{~W} / \mathrm{m}^{2}$ by the end of the twenty-first century.

The list of 32 CMIP5 models and their relevant information are provided in Table 1. For each model, the first ensemble member run has been used and the following variables have been considered in our analysis: SST and 850-hPa zonal wind.

For observed SSTs, we used the Hadley Centre SeaIce and SST dataset (HadISST; Rayner et al. 2003) and the 1958-2005 period.

We focus on the interannual time scale and mainly on SST. The monthly SSTA are first calculated by removing a monthly climatology. The climatology is estimated over the period 1958-2005 for observations and the $\mathrm{H}$

97 simulations, while for RCP 8.5 simulations, the climatology is based on the period 2006-2050. We further detrendedall SST time series with the linear least square method.

99 The canonical ENSO events are determined with the help of the Niño3 index (area-averaged SSTA over $5^{\circ} \mathrm{N}-5^{\circ} \mathrm{S}$, $100150^{\circ} \mathrm{W}-90^{\circ} \mathrm{W}$ ). We also considered the Modoki ENSO events and we used the El Niño Modoki Index (EMI; Ashok 101 et al. 2007), to identify them:

$102 \mathrm{EMI}=[\mathrm{SSTA}] \mathrm{A}-0.5 *[\mathrm{SSTA}] \mathrm{B}-0.5 *[\mathrm{SSTA}] \mathrm{C}$

103 The square bracket in Equation (1) represents the area-averaged SSTA over each of the regions A $\left(165^{\circ} \mathrm{E}-140^{\circ} \mathrm{W}\right.$, $\left.10410^{\circ} \mathrm{S}-10^{\circ} \mathrm{N}\right), \mathrm{B}\left(110^{\circ} \mathrm{W}-70^{\circ} \mathrm{W}, 15^{\circ} \mathrm{S}-5^{\circ} \mathrm{N}\right)$, and $\mathrm{C}\left(125^{\circ} \mathrm{E}-145^{\circ} \mathrm{E}, 10^{\circ} \mathrm{S}-20^{\circ} \mathrm{N}\right)$, respectively.

The IOBM is defined as the SSTA averaged over the region $40^{\circ} \mathrm{E}$ to $110^{\circ} \mathrm{E}$ and $20^{\circ} \mathrm{S}$ to $20^{\circ} \mathrm{N}$ of the Indian ocean (Yang et al. 2007). Finally, the IOD index is computed as the difference between averaged SSTA over western box $\left(50^{\circ} \mathrm{E}-70^{\circ} \mathrm{E}, 10^{\circ} \mathrm{S}-10^{\circ} \mathrm{N}\right)$ and eastern box $\left(90^{\circ} \mathrm{E}-110^{\circ} \mathrm{E}, 10^{\circ} \mathrm{S}-0\right)$ of Indian ocean (Saji et al. 1999).

For convenience, we refer to the boreal summer (June-August; henceforth JJA), fall (September-November; henceforth SON), winter (December through following February; henceforth DJF) and spring (March-May; henceforth MAM) seasons simply as summer, fall, winter and spring.

\section{2.b Selection of CMIP5 models and statistical methods}

To assess the performance of the CMIP5 coupled models in simulating the observed tropical SST interannual variability, a method based on the EOF analysis is used (Bayr and Dommenget 2014; Wang et al. 2015). The principle of the method is as follows: to compare the spatial structure of SST variability of two different datasets, an objective way is (i) to define a set of (spatial) vectors as a common basis, (ii) to project the two datasets onto this common basis, and (iii) to compare the amount of variance described by each vector of the basis for the two datasets. 
Note that these computations require that the two datasets share the same spatial grid. Consequently, we have first interpolated all the CMIP5 outputs onto the HadISST grid, i.e. $1^{\circ} \times 1^{\circ}$, for further analysis. In order to define a common basis for two datasets,,we generate the leading EOF modes from one dataset. These leading EOF modes give a synthetic depiction of the main modes of variability in this dataset. In the next step, we simply project the second dataset onto these (spatial) reference EOF-modes (computed from the first dataset) and estimate the amount of variance that these reference EOF-modes explain in this projected dataset.

In our analysis, we computed the EOF-modes from monthly HadISSTSSTA for the 1958-2005 periodand designate them as the reference modes. We then projected the time series of the $32 \mathrm{H}$ simulations onto these reference modes. For each EOF-mode, there exists a difference between the explained variance (in the first dataset) and the projected explained variance (in the second dataset), subject to the fidelity of the $\mathrm{H}$ simulations. This information is then utilized to generate statistics useful to rank the CMIP5 models, based on their respective performances in replicating the observed interannual variability during 1958-2005.. The main statistic we useis the normalized Root Mean Square Error (RMSE). The normalized RMSE is defined as follows:

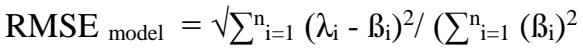

Where

$\mathrm{n}$ is a predefined number of SST reference EOFs (e.g. computed on HadISST dataset), assuming that the EOFs have been ranked in decreasing order of explained variance.

$\lambda_{\mathrm{i}}$ is explained variance from a CMIP5 model onto the reference EOF $\mathrm{i}$;

$\beta_{\mathrm{i}}$ is explained variance from the HadISST dataset onto the reference EOF $i$.

The above normalization allows a better comparison of the RMSE values among different models or datasets with different sampling uncertainties (Wang et al. 2015). A small RMSE value for any model suggests that the model simulates the observed variability of the climate system well. On the other hand, a RMSE value of 100\% corresponds to errors that are as big as the eigenvalues of the selected EOF modes used to define the RMSE statistic. As explained by Wang et al. (2015), in most of the cases, this occurs due to a critical mismatch between the leading EOFs in the two datasets or, alternatively, when modes are mixed or inverted between the two datasets giving an improper distance between the two datasets.

In our analysis, we have used the first 8 reference EOF modes to compute the normalized RMSE. A question that comes immediately to mind is why we used only 8 degrees of freedom. Following Bretherton et al. (1999) and Wang et al. (2015), we first used the concept of the effective spatial number of degrees of freedom in order to determine the number of EOFs to be used to compute the RMSE. However, from our own experience and the work of Sterl et al. (2007), the number of spatial degrees of freedom is a highly non-robust quantity, which is difficult to estimate objectively in practice. Here, we have thus simply computed the RMSE from the first 8 modes, as well as 
values don't change much from five to eight modes. Thus, this suggests that the first 8 reference EOFs form a stable basis for comparing the various datasets and still take into account a large part of the variances in each dataset. Therefore, for the purpose of grouping the CMIP5 models in different categories according to their performance in simulating the observed SST variability, RMSE values computed from first 8 modes are a good compromise.

Finally, standard regression and correlation analyses have also been performed to document the teleconnection patterns and their possible changes in a warming climate.

\section{Model bias and future projections in mean SST and variance}

We document first how the CMIP5 models simulate the annual mean SST and mean variance of SSTA and what are their projected changes. The periods selected for calculating the mean and variance of observation, $\mathrm{H}$ and RCP 8.5 simulations are 1958-2005, and 2006-2050, respectively. Fig. 1a represents the annual mean SST from the ensemble of CMIP5 H simulations. On average, annual mean SST over TP in $\mathrm{H}$ simulations is between $26-28^{\circ} \mathrm{C}$, but the equatorial western TP is warmer then eastern TP as expected (Fig. 1 a). Fig. 1 b displays statistically significant mean bias values of CMIP5 ensemble relative to the HadISST for the same period. The simulated SSTs are clearly too high in the tropical southeastern Pacific and Atlantic and too low in the equatorial Pacific relative to observations, as also noted by many studies (Richter et al. 2015; Wang et al. 2014). Focusing specifically on the TP, this implies that the equatorial SST gradient is severely damped in CMIP5 models on average, with significant implications for ENSO realism in CMIP5 models (Li and Xie 2014). These Pacific SST biases persist from several generations of CMIP models (Reichler and Kim 2008). Over the TIO, the models show warm SST biases. The difference of ensemble mean SST between RCP 8.5 and H simulations of CMIP5 indicates that the simulated SST is significantly increasing over all tropical oceans with mean conditions shifting to an El Niño-like pattern in the TP and a positive IOD like pattern in the TIO(Fig. 1c; Chu et al. 2014). Interestingly, the extent of SST increase is larger over northern tropical oceans compared to southern part, suggesting that the warming pattern in the Pacific is not exactly El Niño like. Over the IO, the projected changes suggest that the western IO and South-East IO, off Australia, will undergo enhanced warming in a global warming scenario (Chu et al. 2014; Zheng et al. 2013). The fidelity of CMIP5 models in simulating the SSTA variance is also assessed (see Fig. 1d-f). Detrended SSTA is used to compute the variance. The largest SST interannual variability is seen in the eastern Pacific, which is mostly associated with ENSO variability. The bias in variance is significantly high over the equatorial western and central Pacific, implying that the ENSO-related SST anomalies are shifted westward in most CMIP5 models (Fig. 1e), consistent with the cold tongue bias affecting most of the CMIP5 models (see Fig. 1b). IO is also affected by exaggerated SST variability, consistent with previous studies (Annamalai et al. 2017). In contrast with the changes in mean SSTs (Fig. 1c), the difference of ensemble variance between H and RCP 8.5 simulations is insignificant everywhere, even in the TP (Fig. 1f). The implications for ENSO, IOBM or IOD teleconnections will be further studied in the next sections. 


\section{SSTA interannual variability in historical CMIP5 simulations}

187 In this section, we focus mainly on the fidelity of the CMIP5 models in representing the observed TIP variability and teleconnections during recent decades (1958-2005) with the help of EOF analysis.

These leading EOF modes have been estimated for three different domains, the TIO $\left(40^{\circ} \mathrm{E}-120^{\circ} \mathrm{E}, 30^{\circ} \mathrm{S}-30^{\circ} \mathrm{N}\right)$, TP $\left(110^{\circ} \mathrm{E}-70^{\circ} \mathrm{W}, 30^{\circ} \mathrm{S}-30^{\circ} \mathrm{N}\right)$ and $\operatorname{TIP}\left(40^{\circ} \mathrm{E}-70^{\circ} \mathrm{W}, 30^{\circ} \mathrm{S}-30^{\circ} \mathrm{N}\right)$.

The first two leading modes of TP represent the ENSO variability and its different types (Fig. 2 a,b; see Ashok et al.

192 2007; Marathe et al. 2015, their Fig. 1). The first leading mode of TIO corresponds to IOBM and explains about

$19340 \%$ of variability (Fig. 2d). The second and third modes of TIO SST variability (Fig. 2e and f) are related with IOD

194 (Saji et al. 1999; Murtugudde et al. 2000) as well as the subtropical IOD (SIOD; Behera and Yamagata 2001),simply

195 because our domain extends up to $30^{\circ} \mathrm{S}$ and we consider all the calendar months in the EOF analysis. A positive 196 SIOD is characterized by cold SST anomalies off Australia and warm SST anomalies in the southwestern IO, 197 south of Madagascar during boreal winter. The spatial EOF patterns of the first two EOFs over the TIP (Fig. 2 g, h) 198 and TP (Fig. 2 a, b) are somewhat similar over the TP. This is consistent with the higher SST variability over the TP compared to the TIO (See Fig. 1d). The dependence of these EOFs to the global warming is also checked by recomputing these EOF patterns on the detrended SSTs (see Fig. 3). The spatial patterns of most of the leading EOFs for the three domains remain,in general, unchanged after detrending. This illustrates that the observed climate change SST signal is projecting on specific modes of SST variability in the TIP. However, for TIP, the $2^{\text {nd }}$ and $3^{\text {rd }}$ modes of "raw" are becoming the $3^{\text {rd }}$ and $2^{\text {nd }}$ modes of detrended SSTs, respectively. The main factor responsible for this reversed order between the $2^{\text {nd }}$ and $3^{\text {rd }}$ EOF modes of observed SSTA with or without detrending seems related the large warming trend over the Indian Ocean warm pool during recent decades (e.g. compare Fig. 2b and Fig. 3c). The explained variance increases approximately by $2 \%$ only for the first leading EOF mode of TP and TIP domain when the EOFs are computed from the detrended SSTA (see Table 2). But, it decreases significantly, i.e., by $10 \%$ for the leading EOF mode of the TIO, which is reminiscent of the IOBM. This suggests that the TIO is mainly responsible of the reversed order between the $2^{\text {nd }}$ and $3^{\text {rd }}$ EOF modes of observed SSTA with or without detrending in the TIP domain. However, the SST trends do not alter the spatial structures of the leading EOF modes in the different oceanic basins, only the variance they described. As we are interested in the interannual variability of TIP, detrended SST data is used throughout our subsequent analysis and, especially, in the computation of the RMSE statistics, which is discussed in the next paragraph.

214 As mentioned earlier, CMIP5 models have been ranked in the ascending order of their RMSE values for the TIP (see 215 Table 3). The RMSE values for TIO and TP domains are also listed in Table 3 to assess the robustness of the results 216 and the dependency to the domain definition. RMSE values for TIP and TP domains are nearly the same, but the 217 corresponding RMSEs of TIO are different, implying that the models performing best for the TP and TIO are not 218 necessarily the same. Table 3 shows that for the first twenty-one models, the RMSE for the TIP domain is below $47 \%$ and beyond that it reaches suddenly a value of nearly $60 \%$. Thus, these first 21 "best" models are selected for 
our subsequent analysis. Unfortunately, the RCP 8.5 data was unavailable for five out of these 21 models. Thus, the number of "best" models available for future projections will become finally 16 for further analysis.

\section{Seasonal evolution of leading modes in $\mathrm{H}$ simulations}

223 The ability of the CMIP5 models to reproduce seasonal cycles of canonical El Niños and that of El Niño Modoki is 224 measured by the comparing the simulated and observed monthly Standard Deviation (SD) of the Niño3 index and El 225 Niño Modoki Index (e.g. EMI) (Ham and Kug 2014).

226 ENSO variability has a strong phase locking to the seasonal cycle with the maximum of SSTA in November-January 227 and minimum in March-May in the eastern Pacific (Ham and Kug 2014; see also Fig. 4a). However, unlike the 228 observations, many individual models show a different seasonal cycle of evolution, with the peak of the canonical El 229 Niño occurring at any season (Jourdain et al. 2013; Taschetto et al. 2014) and only a few models have Niño3.4 SST 230 amplitude similar to or above observations during boreal winter (Taschetto et al. 2014). This can be related to many 231 factors, especially the spatial shift of simulated SST variability over the equatorial Pacific (Li et al. 2019). It is 232 important to consider this deficiency if we want to assess the changes of predictability and lead-lag relationships between the ENSO, IOD and IOBM phenomena in the future projections using CMIP5 models. The observed El Niño Modoki also peaks in December and January similar to canonical El Niño, but the minimum of EMI occurs in May and June, slightly later than the minimum of canonical El Niño (see Fig. 4b). It is noticed that very few models are able to capture the seasonal cycle of the El Niño Modoki. This also has serious implications for simulation of the seasonal cycle and interannual variability of other major climate processes such as the Indian summer monsoon (e.g. Jourdain et al., 2013). Note that, in this section, the seasonal evolution of all the "best" 21 models is discussed, as the $\mathrm{H}$ simulations are available for all of them. From the next section onwards, only those models for which both $\mathrm{H}$ and RCP 8.5 simulations are available will be used (e.g. 16 models).

241 Now, the fidelity of the statistics for IOBM and the IOD will be explored. SD of observed IOBM is maximum in 242 February-March (black curve in Fig. 4c). Many CMIP5 models reproduce this late boreal winter peak in IOBM 243 variability, but the IOBM amplitude is generally overestimated and the inter-model spread is very large (Fig. 4c; Du et al. 2013). The observed IOD is also tightly seasonally phase locked to the calendar months and peaks in SON (black curve in Fig. 4d). In agreement with Jourdain et al. (2016) and Cai et al. (2009), we find that 19 out of 21

246 CMIP5 models overestimate the IOD peak amplitude, in SON (Fig. 4d). In summary, the CMIP5 models have a 247 tendency to overestimate the amplitude of the IO modes (Figs 4c,d), especially the IOD despite of the fact that the TP modes are generally damped in the models (Figs 4a,b).

\section{Changes in SST variability in near future}

250 We now concentrate on those models, which can at least simulate a reasonable phase-locking of ENSO to the annual 251 cycle, as this property is key for the realism of the ENSO teleconnections in the coupled models. To quantify the 252 models' fidelity in simulating the ENSO phase-locking, the correlations between the monthly SD of Niño3 SST 253 anomaly for each model and observations are computed (Ham and Kug 2014). Thus, 9 models are selected out of the

25416 "best" models, which have a significant positive correlation at the $90 \%$ confidence level, (see Table 4 ). Note that 
some of the "best" models exhibit even a strong negative correlation (e.g. CSIRO-Mk3-6-0, IPSL-CM5A-LR, IPSLCM5A-MR). This demonstrates that the CMIP5 models, which performed best for reproducing the observed ENSO variability, are not necessarily the models with the best seasonal phase-locking, highlighting the difficulty of selecting the best CMIP5 models in a universal way. Based on this, we form two groups of models for evaluating the climate projections, namely, Groups A and B: Group A consists of all 16 models. The Group B consists of the 9 models out of the 16 models, which have a reasonable seasonal phase locking of ENSO.

We now focus on the SD changes for theNiño3, EMI, IOBM and IOD indices in the RCP 8.5 simulations. For that purpose, the percentage change of SD from $\mathrm{H}$ to $\mathrm{RCP} 8.5$, for each index is computed as follows:

264 Fig. 5 displays percentage changes in the monthly SD of Niño3 and EMI from H to RCP 8.5 simulations for groups

265 A and B. Furthermore, the standard-error of simulated percentage change in SDs of indices across the models in each group is also calculated for each month (Fig. 5). These error bars give an estimate of the robustness of the change that has occurred across the models. We note that there is a substantial spread in the SD of all indices across the models (Fig. 5). Group A shows a marked increase in the canonical El Niño amplitude in all months (see Fig. 5a). However the models with a reasonable ENSO phase locking (Group B) demonstrate that this increase is coming from models in which the ENSO peak is not observed during boreal winter in the historical period(see Fig. 5b). The Group B of models show strengthening of El Niño in all months except JJA, but the error bars are very large. We thus conclude thatcanonical El Niño variability may increase in the future, but this projected increase is insignificant 273 if we take only into account the models that have realistic ENSO pattern and seasonal cycle in the $\mathrm{H}$ simulations.

274 This result is in agreement with previous studies (Stevenson et al. 2012; Chen et al. 2015; Rashid et al. 2016). The 275 EMI amplitude, on the other hand, seems to increase significantly in the future during its peak for both Group A and 276 Group B models (see Figs. 5c and 5d).

277 We shall now discuss the projected changes of the IOBM and IOD (Fig. 6). The percentage changes in the SD of 278 these indices from $\mathrm{H}$ to RCP8.5 simulations suggest that the simulated IOBM amplitude will weaken in future despite no commensurate robust changes of ENSO (see Figures 6a, b), but the intermodal spread is again relatively large. However, this decrease in IOBM magnitude is robust during early summer for group B (Fig 6b) and is consistent with a similar reduction of Niño3.4 amplitude in this group (Fig 5b). To sum up, these results indicate that, for a high emission scenario, IOBM may not extend till the next boreal summer in future, and hence may contribute less to the Indian summer monsoon variability (Yang et al. 2007). On the other hand, the SD of IOD is seen to amplify in Group A as well as in Group B models (see Fig. 6c, d) during boreal summer as the error barsare well above zero. This suggests a strengthening, and an early onset of IOD events.

\section{Changes in the lead-lag correlations between ENSO, IOD and IOBM}

288 We now investigate whether the ENSO, IOD and IOBM relationships will change under anthropogenic global 289 warming. From this section, we will discuss only the relationship between Niño3, IOD and IOBM indexes because EMI relationship with IOD and IOBM is not completely known yet in observations. 
The concurrent relationship among ENSO, IOD and IOBM is assessed with the help of a correlation analysis between the different pairs of climate indices during their respective peak season in the H and RCP 8.5 simulations (Table 5). In this context, Table 5 displays the "simultaneous" correlations among IOD (SON), Niño3 (DJF) and IOBM (MAM) for observations and Groups A and B models. Here, "simultaneous" means that IOD (during SON) precedes both Niño3 and IOBM (during the following DJF and MAM seasons), and Niño3 (during DJF) precedes the IOBM by two months. Note first that all the correlations listed in Table 5 are positive and statistically significant at the $90 \%$ confidence level for both observations and CMIP5 models.

In the observations, the canonical El Niño peak in boreal winter is preceded by positive IOD peak in the previous boreal fall, and is followed by the peaking of the IOBM during boreal spring. Due to the tight relationship between IOD and Niño3 on one hand and between Niño3 and IOBM on the other hand, the correlation between IOD and IOBM is also positive and significant (Hong et al. 2010). The full multi-model mean (e.g. Group A) realistically simulates these significant "simultaneous" positive correlations among IOD, ENSO and IOBM during their respective peak phases in the $\mathrm{H}$ simulations, despite weaker amplitude, in agreement with Ha et al. (2016). These simultaneous correlations in the $\mathrm{H}$ simulations are generally further improved if we consider only models in Group B(e.g. see second row in Table 5). Furthermore, the inter-model spread also decreases from Group A to B models, which gives even more confidence in the models in Group B for assessing future changes. These simultaneous correlations between IOD, Niño3 and IOBM are, in general, seen to slightly increase in the RCP 8.5 simulations, especially for Group B. There is only one exception to this general rule, the correlation between IOD and Niño3 in Group A. Notably, the association of IOBM with both Niño3 and IOD becomes stronger in the future relative to the $\mathrm{H}$ period. The inter-model spread is also slightly increasing from $\mathrm{H}$ to RCP 8.5 simulations with one important exception, which concerns again the association between Niño3 and IOBM. However, this intermodel spread remains quite low, especially for Group B in the RCP 8.5 simulations, suggesting the robustness of these results. Next, we try to detect if there are any changes from H to RCP 8.5 simulations in the lead relationships between the IO indexes and the Niño3 index, which will have implications for ENSO predictability (Luo et al. 2010; Izumo et al. 2010; Cai et al. 2019) in the background of increasing anthropogenic warming. A large number of studies have pointed out the role of IOBM in ENSO transitions (Kug and Kang 2006; Obha and Ueda 2007; Terray et al. 2016). IOBM is able to trigger low-level easterly wind anomalies over the western equatorial Pacific Ocean, which promote eastward propagating upwelling Kelvin waves in the equatorial Pacific Ocean during boreal spring (Kug and Kang 2006; Obha and Ueda 2007; Wang 2019). These easterly wind anomalies over the western Pacific are most significant during and just after the El Niño peak phase and thus hasten the transition from El Niño to La Niña. However, importantly, the observed correlations for the H period (shown in Table 6), between the MAM(0) IOBM and $\mathrm{D}(0) \mathrm{JF}(1)$ Niño3, i.e. when IOBM leads, are quite modest (i.e. -0.17) and statistically not significant for both observations and Group A. We ascertained the result by employing the Niño3.4 index in place of Niño3 index in the correlation analysis (not shown). This suggests that not all IOBM events condition the El Niño to La Niña transition in the TP or, alternatively, that the IOBM feedback on ENSO occurs in another season. This result is strange, but interesting because while Group A is able to capture this observed relationship with a high fidelity, Group B, which 
has a more realistic phase-locking to the annual cycle, on the other hand, tends to overestimate the link between IOBM during MAM and the ENSO state in the next boreal winter in the $\mathrm{H}$ simulation (Table 6). However, in the future projections, the correlation with springtime IOBM leading wintertime Niño3 index is much more negative and becomes statistically significant at $90 \%$ confidence level for both groups A and B. This suggests that the role of IOBM in speeding the transition from El Niño to La Niña is more significant in the RCP 8.5 projections despite of the decrease of IOBM amplitude during late boreal spring and early summer highlighted in the preceding section. We now focus on the fidelity of CMIP5 models in simulating the observed tendency of ENSO events to follow the IOD events in the previous year and the projected changes for this behavior in the RCP 8.5 simulations (see Table 6; Izumo et al. 2010; Jourdain et al. 2016). The relevant correlations between SON(-1) IOD and D(0)JF(1) Niño3 indexes (e.g. when IOD leads by more than one year the Niño3 index) are shown in Table 6. The lead correlations of the IOD index with Niño3 index 14 months later are, respectively, $-0.39,-0.35$ and -0.41 for observations, Group A and $\mathrm{B}$ in the $\mathrm{H}$ period. These values are in good agreement with previous results based on observations and $\mathrm{H}$ simulations (Izumo et al. 2014; Jourdain et al. 2016). These correlations are significant at the $90 \%$ confidence level and have stronger amplitude than the corresponding IOBM-Niño3 correlations discussed above, despite of the longer time lead. However, in the RCP8.5 simulations, these lead correlations of the IOD with Niño3 14 months later are all decreasing, especially for Group B, despite the "simultaneous" correlations between IOD and Niño3 indexes are almost stable between the H and RCP 8.5 simulations (see Table 5; Chu et al. 2014). The above conclusions are made based on the lead-lag correlation between IOD, IOBM and Niño3 SST time series in their respective peak seasons. In order to illustrate the associated evolution of SSTA in the TIP domain and how these SST patterns change from H to RCP8.5 simulations, we selected two typical individual models from Group B, which perform best according to our two selections rules (based on least normalized RMSE and a realistic seasonal phase-locking), namely, the GISS-E2-H-CC and ACCESS1-0 models (see Tables 3 and 4). Importantly, the GISSE2-H-CC shows the largest absolute amplitude increase (e.g. by 0.32) in IOBM-Niño3 lead correlations and ACCESS1-0 shows the largest absolute amplitude decrease (e.g. of 0.43) in IOD-Niño3 lead correlation from $\mathrm{H}$ to RCP 8.5 simulations in Group B, making them interesting candidates for illustration of possible physical mechanisms behind the changes of the lead-lag correlations between the climate indexes in the future projections. First, Figures 7ab confirm that the role of IOBM in the negative feedback of the IO on ENSO has considerably strengthened in the GISS-E2-H-CC simulations, as both the magnitude and extent of the negative correlations over TP have increased considerably several months after the occurrence of IOBM events from H to RCP 8.5 simulations for this model. The results from a complementary regression analysis also show that the amplitude of the associated SSTA increases considerably from the H to RCP 8.5 simulations (Fig. S1a and b). On the other hand, the IODNiño3 lead correlation and regression SSTA patterns simulated by ACCESS1-0 drastically drop and become insignificant in future projections (Figs. 7cd and S1cd), also in full agreement with the results from the analysis of the correlations between the indices (Table 6). wind anomalies for positive and negative IOBM (IOD) events in the GISS-E2-H-CC (ACCESS1-0) simulations (Figs. 8 and 9). 
In case of GISS-E2-H-CC, first we calculated standardized index of boreal spring (MAM) IOBM. We selected 11 strong positive IOBM events when the standardized IOBM index is above the 0.7 threshold and 10 negative IOBM events when it is below -0.7 in the $\mathrm{H}$ simulations. Following a similar procedure for future projections, we got 12 positive IOBM events and 11 negative IOBM events in the RCP 8.5 simulations. Comparing the SST and 850-hPa wind anomalies evolution following the positive IOBM events in the two periods (i.e., Fig. 8a and 8b) for GISS-E2$\mathrm{H}-\mathrm{CC}$, we find that though a basin-wide IO warming is observed during MAM of year 0 in present period, it's magnitude is moderate and hence it is not able to trigger significant easterly wind anomalies over the western

372 Pacific, which may fasten the turnabout of ENSO during year 0, and finally a very weak La Niña event is simulated

373 in TP at the end of year 0. In contrast, in the future warming scenario, a stronger positive IOBM is seen during

374 MAM of year 0 accompanied by more significant and stronger easterlies over the western TP at the beginning of 375 year 0 , which trigger a well-defined La Niña event at the end of year 0 (Fig. 8b). Interestingly, the changes from the $376 \mathrm{H}$ to RCP 8.5 simulations for the GISS-E2-H-CC model concern mainly these positive IOBM events. Negative 377 IOBM events during MAM of year 0 seem to give rise to moderate El Niño conditions at the end of year 0 in both $\mathrm{H}$ and RCP 8.5 simulations (Fig. 8c and d) despite of the fact that westerlies over the western TP during boreal spring of year 0 are much better defined in the RCP 8.5 simulation. This suggests that global warming induces a stronger nonlinearity in the relationship between IOBM and ENSO (Ohba and Watanabe 2012). Following a similar procedure, we selected 11 positive IOD events when standardized IOD index during SON is above 0.7 and 11 negative IOD events when it is below -0.7 in the $\mathrm{H}$ simulation of the ACCESS1-0 model. For future projection, we got 13 positive IOD events and 13 negative IOD events. The Hovmöllercomposites of SST and 850-hPa zonal wind anomalies in the TIP domain during the $\mathrm{H}$ period highlight a very systematic statistical relationship between both positive and negative IOD events and the evolution of TP SST anomalies in the following year consistent with previous studies (Fig. 9; Izumo et al. 2010, 2014; Jourdain et al. 2016). However, as noted by Jourdain et al. (2016), the physical mechanisms responsible for this relationship remain elusive because associated $850-\mathrm{hPa}$ zonal wind anomalies over the western TP at the beginning of year +1 remain weak and are not significant for both positive and negative IOD events simulated by the ACCESS1-0 model (Fig. 9a and c).Moreover, the main result is that the role of IOD events in ENSO turnabout is becoming almost negligible in the RCP 8.5 simulation performed with the ACCESS1-0 model (Fig. 9b and d). Interestingly, this weaker role of IOD in ENSO evolution is accompanied by a change of the spatial structure of the IOD events during SON, which seem exclusively under the control of the eastern IOD pole SST anomaly in the future projection by contrast with what is observed in the $\mathrm{H}$ period (Fig. $9 \mathrm{~b}$ and d)..

In summary, the above analysessuggest an increasing role of positive IOBM events in ENSO turnabout and a stronger asymmetry in the relationship between IOBM and ENSO while the ENSO-IOD link may become weaker in the future under global warming. Implications for future changes in the "global" negative feedback of the IO on ENSO and the long lead predictability of Niño3 SST index from IO SST modes are discussed in next section. 


\section{Changes in IO negative feedback and predictability of ENSO indices from IO SST}

In this section, we examine the collective and respective influences of IOD, IOBM and also Niño3 persistence on the "potential" predictability of Niño3 SST anomalies in the following year (e.g. end of year 0 and beginning of year +1 ) in the $\mathrm{H}$ simulations realm, and corresponding future projections, using a multiple linear regression approach. Table 7 lists the values of coefficient of determination, i.e. $\mathrm{R}^{2}$, for the (multiple) linear prediction of Niño3 at the start of year +1 (e.g. D of year 0 and JF of year +1 ) using different predictors such as Niño3 in DJF of year 0, IOD in SON of year -1 or IOBM in MAM of year 0 , and their different combinations using the CMIP5 models. An $\mathrm{R}^{2}$ between 0 and 1 indicates the extent (e.g. percentage) to which the variance of the dependent variable is explained by the predictors. As an illustration, an $\mathrm{R}^{2}$ of 0.10 means that $10 \%$ of the variance of the dependent variable is predictable/described from the selected predictors. Here, we also compare how the predictability of Niño3 in DJF would change from $\mathrm{H}$ to RCP 8.5 for each set of predictors.

In the $\mathrm{H}$ period, the IOD in SON of year -1 is a better predictor than IOBM for observations, as well as groups A and B. Niño3 autocorrelation does not seem to play any significant role in the $\mathrm{H}$ period (Table 7 first row). However, in the global warming scenario, results are different: the IOBM $\left(R^{2}=0.22\right.$ for Group B) plays a more important role than IOD $\left(\mathrm{R}^{2}=0.15\right.$ for Group $\left.\mathrm{B}\right)$ in the Niño3 prediction, consistent with the results in the last section. The Niño3 SST "potential" predictability is improved and enhanced in the future if we consider IOBM and IOD together as predictors $\left(\mathrm{R}^{2}=0.25\right.$ for Group $\mathrm{B}$ ) as compared to IOBM or IOD alone (see Table 7). Interestingly, Niño3 and IOBM perform even better $\left(\mathrm{R}^{2}=0.26\right.$ for Group B) than the pair IOBM and IOD in the RCP 8.5 simulation. This confirms the leading role of IOBM in the RCP 8.5 simulation.We also get improved prediction for Niño3 from H to RCP 8.5 simulations for both groups A and B if we take Niño3 SST, IOD and IOBM all together or, alternatively, the pairs IOBM and IOD or IOBM and Niño3. This demonstrates that the "global" negative feedback of IO on ENSO turnabout increases in the RCP 8.5 simulations, despite IOD is losing its predictive value. However, the inter-model variability is always increasing in the RCP 8.5 simulations for all the regressions performed in Table 7.

One well-known drawback of $\mathrm{R}^{2}$ is that it can be driven to any desired value simply by adding predictors. To overcome this effect, we also used adjusted $\mathrm{R}^{2}$ statistics (Table 8), which indicate the proportional reduction in the mean square rather than in the sum of squares (Draper and Smith 1998). The purpose of using adjusted $\mathrm{R}^{2}$ is to check whether the predictive value is actually improved when a combination of the Niño3, IOBM and IOD is considered, and not just because of increasing number of predictors. From Table 8, it is clear again that for Niño3 prediction in the future, considering IOBM and IOD together as predictors would be beneficial $\left(\mathrm{R}^{2}=0.21\right.$ for Group $\mathrm{B}$ ), instead of just taking IOBM (adjusted $\mathrm{R}^{2}=0.2$ for Group B) or IOD (adjusted $\mathrm{R}^{2}=0.13$ for Group B) alone. However, in the future, the pair IOBM and Niño3 (adjusted $\mathrm{R}^{2}=0.23$ for Group B) performs again better that the pair IOBM and IOD using adjusted $\mathrm{R}^{2}$. We also get again marginally "best" results if we consider all together Niño3, IOBM with IOD (adjusted $\mathrm{R}^{2}=0.24$ for Group B). 
Of course, we should also be mindful from the above discussion on the $\mathrm{R}^{2}$ and adjusted $\mathrm{R}^{2}$ values, that all these SST predictors can explain only 20-29\% of Niño3 variability at most and, thus, have strong limitations compared to more traditional ENSO predictors such as the equatorial Pacific WWV or low-level zonal wind anomalies over the western Pacific (Clarke 2008). But the above discussion gives us a qualitative but useful interpretation of the changing strength of the negative feedback of the IO on ENSO.

\section{Summary and discussion}

A large set of CMIP5 coupled models are analyzed to assess the present (e.g. 1958-2005) and near future (e.g. 20062050) of ENSO and TIO modes of variability and their teleconnections.

444 First, a method based on EOF analysis is employed for selecting 16 CMIP5 models out of 32, which perform best to 445 simulate TIP SST variability during recent decades, for further analysis. Despite these 16 CMIP5 models perform 446 best in simulating the spatial patterns of observed SST variability, many of them have difficulties in simulating the seasonal phase locking of canonical El Niño events during the $\mathrm{H}$ period.Thus, we further selected a subset of 9 models with a realistic ENSO seasonal phase-locking during recent decades(out of the 16) for evaluation of the robustness of future changes.

We then discussed how the leading modes of TP and TIO would change in terms of amplitude and seasonal phaselocking under global warming. The results infer that canonical El Niñomay not change much in the near future. On the other hand, EMI amplitude seems to increase significantly during its peak season in the near future. In case of TIO modes, it is found that the IOBM is projected to be weaker during early summer in the RCP8.5 scenario. For the IOD, while its amplitude may not change significantly during boreal fall, it is projected to strengthen during boreal summer, pointing to an early onset of IOD events in a future scenario. Interestingly, our results are broadly in agreement with Chu et al. (2014), despite that these authors used the RCP4.5 scenario at the end of the $21^{\text {st }}$ century; but we focused on a high RCP8.5 emission scenario and a near future period with a different model selection method.

459 Next, we focus on the changes from H to RCP 8.5 simulations in the lead relationships between the IO and Niño3 460 indexes. Lead correlation between IOBM MAM(0) and Niño3 $\mathrm{D}(0) \mathrm{JF}(1)$ is very weak for the present period, which 461 suggests that not all IOBM events condition the El Niño to La Niña transitions in the TP. However, the role of 462 IOBM in hastening the El Niño to La Niña transition is much more significant in the RCP 8.5 projections. 463 Interestingly, the lead correlations of IOD with ENSO follow a reversed evolution and IOD is losing its ENSO 464 predictive value in the near future. These results are again consistent with the results of Chu et al. (2014). These 465 changes have been further illustrated by a detailed composite analysis of the evolution of 850-hPa zonal wind and 466 SST anomalies in two typical models viz., GISS-E2-H-CC and ACCESS1-0. Overall, these composite analyses 467 suggest an increasing role of positive IOBM events in ENSO turnabout (thus a stronger asymmetry in the relationship between IOBM and ENSO) and points towards weaker ENSO-IOD correlation under global warming, especially the lead relationship between IOD events and the SST evolution in the TP during the following year.Interestingly, this weaker role of IOD in ENSO evolution in the RCP 8.5 simulation of the ACCESS1-0 
471 modelis accompanied by a change in the spatial structure of IOD, which shows a predominant contribution of the 472 eastern IOD pole in the future.

473 Finally, we also examined the collective and respective influences of IOD and IOBM on the "potential" 474 predictability of $\mathrm{Niño} 3$ in the following year in the $\mathrm{H}$ simulations realm, and corresponding future projections, using

475 a multiple linear regression approach. Our results show that the "global" negative feedback of IO on ENSO 476 turnabout increases significantly in the RCP 8.5 simulations, despite IOD is losing its predictive value in the future 477 projections.

478 In a nutshell, this study brings out the increasing role of IOBM and negative IO feedback in ENSO transitions in 479 near future. We admit that inter-model spread in CMIP5 ensemble is a big hurdle, which surely limits the degree of robustness of our analysis despite our careful selection of the most "realistic" models. In future, we hope to seek for improved models, which will have a better representation of ENSO, IOD and IOBM. We expect that the new

482 CMIP6 simulations would serve this purpose better. In parallel, it is particularly important to build more efficient metrics for model selection in both the CMIP5 and CMIP6 ensembles for a robust assessment of future climates changes.

\section{Acknowledgments}

487 Weacknowledge the climatemodeling groups, the Program for Climate Model Diagnosis and Intercomparison, and the World Climate Research Programme's working Group on coupled modelling, for making available the "CMIP5" multi-model data sets.

\section{References}

Alexander MA, Bladé I, Newman M, Lazante JR, N-C Lau and Scott JD (2002) The atmospheric bridge: The influence of ENSO teleconnections on air-sea interaction over the global oceans. J Clim 15 2205-2231 simulation: Importance of equatorial Indian Ocean processes. J Clim 30 8159-8178 doi: 10.1175/JCLI-D-16-0573.1 summer monsoons. Clim Dyn 42 1043-1052 https://doi.org/10.1007/s00382-012-1625-4 summer monsoon rainfall. J Natural Hazards DOI 10.1007/s11069-006-9091-0

500 Ashok K, Guan Z and Yamagata T (2003) A look at the relationship between the ENSO and the Indian Ocean dipole 501 J Met Soc Japan $8141-56$

502 Bayr T, Dommenget D (2014) Comparing the spatial structure of variability in two datasets against each other on the 503 basis of EOF-modes. Clim Dyn 42 1631-1648 https://doi.org/10.1007/s00382-013-1708-x 
Behera SK, Luo JJ, Masson S, Rao SA, Sakuma H and Yamagata T (2006) A CGCM study on the interaction between IOD and ENSO. J Clim 19 1608-1705

Behera SK and Yamagata T(2001) Subtropical SST dipole events in the southern Indian Ocean. Geophys Res Lett 28 327-330 doi:10.1029/2000GL011451

Bellenger et al (2014) ENSO representation in climate models: from CMIP3 to CMIP5. Clim Dyn Volume 42 Issue 7, pp 1999-2018

Boschat G, Terray P and Masson S (2012) Robustness of SST teleconnections and precursory patterns associated with the Indian summer monsoon. Clim Dyn 38 2143-2165 doi:10.1007/s00382-011-1100-7

Bretherton CS, Widmann M, Dymnikov VP, Wallace JM and Bladé I (1999) The Effective Number of Spatial $\begin{array}{lllllll}\text { Degrees of Freedom of a Time-Varying Field. J } & \text { Clim } 12 & \text { 1990-2009 }\end{array}$ doi: http://dx.doi.org/10.1175/15200442(1999)012<1990:TENOSD>2.0.CO;2

Cai W et al (2019) Pantropical climate interactions. Science 363:6430 doi: 10.1126/science.aav4236

Cai W, Santoso A, Wang G, Weller E, Wu Lixin, Ashok K et al (2014) Increased frequency of extreme Indian Ocean Dipole events due to greenhouse warming. Nature 510:254-258

Cai W, Sullivan A, and Cowan T (2009) Climate change contributes to more frequent consecutive positive Indian Ocean Dipole events. Geophys Res Lett 36 L23704 doi:10.1029/2009GL040163

Chen L, Tim Li and Yu Y (2015) Causes of Strengthening and Weakening of ENSO Amplitude under Global Warming in Four CMIP5 Models. J Clim 28 3250-3274 doi: http://dx.doi.org/10.1175/JCLI-D-14-00439.1

Chu J-E et al (2014) Future change of the Indian Ocean basin-wide and dipole modes in the CMIP5. Clim Dyn 43:535-551 DOI 10.1007/s00382-013-2002-7

Clarke AJ (2008) An Introduction to the Dynamics of El Niño and the Southern Oscillation. London: Academic Press pp 308

Collins M, An S-I, Cai W et al (2010) The impact of global warming on the tropical Pacific Ocean and El Niño. Nat Geosci 3:391-397 doi: 10.1038/NGEO868

Cowan T, Cai W, Benjamin Ng, and England M (2015) The Response of the Indian Ocean Dipole Asymmetry to Anthropogenic Aerosols and Greenhouse Gases. J Clim 28 2564-2583 doi: http://dx.doi.org/10.1175/JCLI-D-1400661.1

Cretat J, Terray P, Masson S, Sooraj KP and Roxy MK (2017) Indian Ocean and Indian Summer Monsoon: relationships without ENSO in ocean-atmosphere coupled simulations. Clim Dyn 49 1429-1448 doi:10.1007/s00382-016-3387-x 
534 Cretat J, Terray P, Masson S and Sooraj KP (2018) Intrinsic precursors and timescale of the tropical Indian Ocean 535 Dipole : Insights from partially decoupled experiment. Clim Dyn Vol. 51 1311-1352 doi:10.1007/s00382-017-39565367

537 Dayan H, Izumo T, Vialard J, Lengaigne M, Masson S (2014) Do regions outside the tropical Pacific influence 538 ENSO through atmospheric teleconnections? Clim Dyn pp 1-19 doi:10.1007/s00382-014-2254-x

539 Draper N and Smith H (1998) Applied Regression Analysis, Third Edition, New York: John Wiley\& Sons

540 Du Y, Xie S, Yang Y, Zheng X, Liu L, and Huang G (2013) Indian Ocean Variability in the CMIP5 Multimodel

541 Ensemble: The Basin Mode. J Clim 26 7240-7266 https://doi.org/10.1175/JCLI-D-12-00678.1

542 Fischer AP, Terray P, Guilyardi E, Gualdi S, and Delecluse P (2005) Two independent triggers for the Indian Ocean 543 Dipole zonal mode in a coupled GCM. J Clim 18 3428-3449

544 Gualdi S, Navarra A, Guilyardi E and Delecluse P (2003) Assessment of the tropical Indo-Pacific climate in the 545 SINTEX CGCM. Ann Geophys 46 1-26

546 Ha K-J, Chu J-E, Lee J-Y, Yun K-S (2016) Interbasin coupling between the tropical Indian and Pacific Ocean on 547 interannual timescale: observation and CMIP5 reproduction. Clim Dyn doi: 10.1007/s00382-016-3087-6

548 Ham YG, Kug JS (2014) ENSO phase-locking to the boreal winter in CMIP3 and CMIP5 models. Clim Dyn 43 (1549 2) $305-318$

550 Ham YG, Choi JY and Kug JS (2017) The weakening of the ENSO-Indian Ocean Dipole coupling strength in recent 551 decades. Clim Dyn 49(1-2) 249-261

552 Hong CC, Li T, Lin Ho, Chen YC (2010) Asymmetry of the Indian Ocean basinwide SST anomalies: Roles of 553 ENSO and IOD. J Clim 23:3563-3576 doi: 10.1175/2010JCLI3320.1

554 Hu K, Huang G, Zheng XT, Xie SP, Qu X, Du Y, Liu L (2014) Interdecadal variations in ENSO influences on 555 Northwest Pacific-East Asian early summertime climate simulated in CMIP5 Models. J Clim 27 (15) 5982-5998

556 Izumo T, Lengaigne M, Vialard J, Luo J-J, Yamagata T, Madec G (2014) Influence of Indian Ocean Dipole and 557 Pacific recharge on following year's El Niño: interdecadal robustness. Clim Dyn 42 291-310 558 https://doi.org/10.1007/s00382-012-1628-1

559 Izumo $\mathrm{T}$ et al (2010) Influence of the state of the Indian Ocean Dipole on the following year's El Nino. Nature 560 Geoscience 3(3) 168-172

561 Jha B, Zeng-Zhen Hu, Arun Kumar (2014) SST and ENSO variability and change simulated in historical 562 experiments of CMIP5 models Clim Dyn 42:2113-212, DOI 10.1007/s00382-013-1803-z 

monsoon and its relationship to ENSO and IOD in reanalysis data and the CMIP3/CMIP5 simulations. Clim Dyn 41

565 3073- 3102 doi:10.1007/s00382-013-1676-1

566 Jourdain NC, Lengaigne M, Vialard J, Izumo T, Gupta AS (2016) Further insights on the influence of the Indian 567 Ocean dipole on the following year's ENSO from observations and CMIP5 models. J Clim 29:637-658

569 Klein SA, Soden BJ, Lau NC (1999) Remote sea surface temperature variations during ENSO: evidence for a 570 tropical atmospheric bridge. J Clim 12:917-932

571 Krishnaswamy J, Srinivas V, Balaji R, Bonell M, Sankaran M, Bhalla RS, Badiger S (2014) Non-stationary and 572 non-linear influence of ENSO and Indian Ocean Dipole on the variability of Indian monsoon rainfall and extreme 573 rain events. Clim Dyn 1-10. doi:10.1007/s00382-014-2288-0

574 Kug JS, Kang IS (2006) Interactive feedback between ENSO and the Indian Ocean. J Clim 19:1784-1801

575 Li G, Xie S-P (2014) Tropical biases in CMIP5 multimodel ensemble: the excessive equatorial Pacific cold tongue 576 and double ITCZ problems. J Clim 27:1765-1780

577 Li G, Xie S-P, Du Y (2016) A Robust but Spurious Pattern of Climate Change in Model Projections over the 578 Tropical Indian Ocean. J Clim 29 5589:5608

579 Li G, Jian Y, Yang S et al (2019) Effect of excessive equatorial Pacific cold tongue bias on the El Niño-Northwest 580 Pacific summer monsoon relationship in CMIP5 multi-model ensemble. Clim Dyn 52:6195-6212

581 Liu Z, Vavrus S, He F, Wen N and Zhong Y (2005) Rethinking tropical ocean response to global warming: The 582 enhanced equatorial warming. J Clim 18 4684-4700

583 Luo J-J et al (2010) Interaction between El Niño and Extreme Indian Ocean Dipole. J Clim 584 doi:10.1175/2009JCLI3104.1

585 Marathe S, Ashok K, Swapna P, Sabin TP (2015) Revisiting El Niño Modokis. Clim Dyn 45 3527-3545 586 https://doi.org/10.1007/s00382-015-2555-8

Murtugudde R, McCreary JP and Busalacchi AJ (2000) Oceanic processes associated with anomalous events in the 589 Indian Ocean with relevance to 1997-1998. J Geophys Res 105 (C2), 3295-3306

590 Ohba M and Ueda H (2007) An impact of SST anomalies in the Indian Ocean in acceleration of the El Niño to La 591 Niña transition. J Meteor Soc Jpn 85:335-348

592 Ohba M and Watanbe M (2012) Role of the Indo-Pacific Interbasin Coupling in Predicting Asymmetric ENSO 593 Transition and Duration. J Clim 25, 3321-3334

594 Rashid HA, Hirst AC, Marsland SJ (2016) An atmospheric mechanism for ENSO amplitude changes under an 
597 Rayner NA, Parker DE, Horton EB, Folland CK, Alexander LV, Rowell DP, Kent EC, Kaplan A (2003) Global

598 analyses of sea surface temperature, sea ice, and night marine air temperature since the late nineteenth century. J

599 Geophys Res 108(D14) 4407 doi: 10.1029/2002JD002670

600 Reichler T and Kim J (2008) How well do coupled models simulate today's climate? Bull Amer Meteorol Soc 89 $601 \quad 303-311$

602 Richter I (2015) Climate model biases in the eastern tropical oceans: Causes, impacts and ways forward. Clim 603 Change $6345-358$

604 Roxy M, Drbohlav H-K L, Gualdi S, Navarra A (2011) Seasonality in the relationship between El Nino and Indian 605 Ocean dipole. Clim Dyn 37 (1) doi: 10.1007/s00382-010-0876-1 221-236

606 Roxy MK, Rikita K, Terray P and Masson S (2014) The curious case of Indian Ocean Warming. J Clim Vol. 27, 607 8501-8508 doi:10.1175/JCLI-D-14-00471.1

608 Saji NH (2018) The Indian Ocean Dipole. Oxford Research Encyclopedia of Climate Science 609 https://oxfordre.com/climatescience/view/10.1093/acrefore/9780190228620.001.0001/acrefore-9780190228620-e-

$610 \quad 619$

611 Saji NH, Goswami BN, Vinayachandran PN and Yamagata T (1999) A dipole mode in the tropical Indian Ocean. $612 \quad$ Nature $401360-363$

613 Shinoda T, Hendon HH and Alexander MA (2004) Surface and subsurface dipole variability in the Indian Ocean 614 and its relation with ENSO. Deep Sea Res 51 619-635

615 Sterl A, van Oldenborgh GJ, Hazeleger W, Burgers G (2007) On the robustness of ENSO teleconnections. Clim Dyn 616 29:469-485 doi: 10.1007/s00382-007-0251-z

617 Stevenson SL (2012) Significant changes to ENSO strength and impacts in the twenty-first century: Results from 618 CMIP5. Geophys Res Lett 39:1-5 doi: 10.1029/2012GL052759

619 Sun S, Lan J, Fang Y, T, and Gao X (2015) A Triggering Mechanism for the Indian Ocean Dipoles Independent of 620 ENSO. J Clim 28 5063-5076 https://doi.org/10.1175/JCLI-D-14-00580.1

621 Tao W, Huang G, Hu K, Qu X, Wen G, Gong H (2015) Interdecadal modulation of ENSO teleconnections to the 622 Indian Ocean Basin Mode and their relationship under global warming in CMIP5 models. International Journal of 623 Climatology 35: 391-407. 
624 Taschetto AS, Sen Gupta A, Jourdain NC, Santoso A, Ummenhofer CC and England MH (2014) Cold Tongue and

625 Warm Pool ENSO Events in CMIP5: Mean State and Future Projections. J Clim 27 2861-

626 2885.doi: http://dx.doi.org/10.1175/JCLI-D-13-00437.1

627 Taylor KE, Stouffer RJ and Meehl GA (2012) An overview of CMIP5 and the experiment design. Bull Amer 628 Meteor Soc 93 485-498 doi:10.1175/BAMS-D-11-00094.1

629 Terray P, Masson S, Prodhomme C, Roxy MKand Sooraj KP (2016) Impacts of Indian and Atlantic oceans on 630 ENSO in a comprehensive modeling framework. Clim Dyn Vol. 46, 2507-2533, doi:10.1007/s00382-015-2715-x

631 Vecchi GA, Clement A and Soden BJ (2008) Examining the Tropical Pacific's Response to Global Warming EOS, 632 Trans Amer Geophys Union v.89(9) 81-83

633 VonStorch H and Zwiers FW (1999) Statistical analysis in climate research. Cambridge University Press, 484 pp.

634 ISBN 0521450713

635 Wang C (2019) Three ocean interactions and climate variability: a review and perspective. Clim Dyn 53:5119-5136

636 Wang C, Zhang L, Lee S, Wu L, Mechoso CR (2014) A global perspective on CMIP5 climate model biases. Nature

637 Climate Change 4 201-205 DOI: 10.1038/NCLIMATE2118

638 Wang G, Dommenget D, Frauen C (2015) An evaluation of the CMIP3 and CMIP5 simulations in their skill of 639 simulating the spatial structure of SST variability. Clim Dyn 44 95-114 DOI 10.1007/s00382-014-2154-0

640 Wang H, Kumar A, Murtugudde R et al (2019) Covariations between the Indian Ocean dipole and ENSO: a 641 modeling study. Clim Dyn 53 5743-5761 https://doi.org/10.1007/s00382-019-04895-x

642 Weare BC (2013) El Nino teleconnections in CMIP5 models. Clim Dyn 41:2165-2177DOI 10.1007/s00382-012$643 \quad 1537-3$

644 Weller E et al (2016) Human-caused Indo-Pacific warm pool expansion. Science Advances, 645 Vol. 2, no. 7, e1501719 DOI: 10.1126/sciadv.1501719

646 Xie SP, Kosaka Y, Du Y et al (2016) Indo-western Pacific Ocean capacitor and coherent climate anomalies in post647 ENSO summer: a review. Adv Atmos Sci 33:411-432 doi: 10.1007/s00376-015-5192-6

648 Yang Y, Xie SP, Wu L, et al (2015) Seasonality and predictability of the Indian Ocean dipole mode: ENSO forcing 649 and internal variability. J Clim 28:8021-8036 doi: 10.1175/JCLI-D-15-0078.1

650 Yang J, Liu Q, Xie SP, Liu Z, and Wu L (2007) Impact of the Indian Ocean SST basin mode on the Asian summer 651 monsoon. Geophys Res Lett 34 L02708 doi:10.1029/2006GL028571

652 Zhang $\mathrm{T}$ and Sun D (2014) ENSO Asymmetry in CMIP5 Models. J Clim 27 4070-4093 653 doi: http://dx.doi.org/10.1175/JCLI-D-13-00454.1

654 Zhao S, Jin F-F and Stuecker MF (2019) Improved Predictability of the Indian Ocean Dipole Using Seasonally 655 Modulated ENSO Forcing Forecasts. Geophys Res Lett 46 9989-9990. doi:10.1029/2019GL084196 
656 Zheng XT, Xie SP, Du Y, et al (2013) Indian ocean dipole response to global warming in the CMIP5 multimodel 657 ensemble. J Clim 26:6067-6080 doi: 10.1175/JCLI-D-12-00638.1

658 Zheng X-T, Xie SP, Liu Q (2011) Response of the Indian Ocean Basin mode and its capacitor effect to Global 659 Warming. J Clim 24 6146-6164 
(a) $\mathrm{Nino3}$

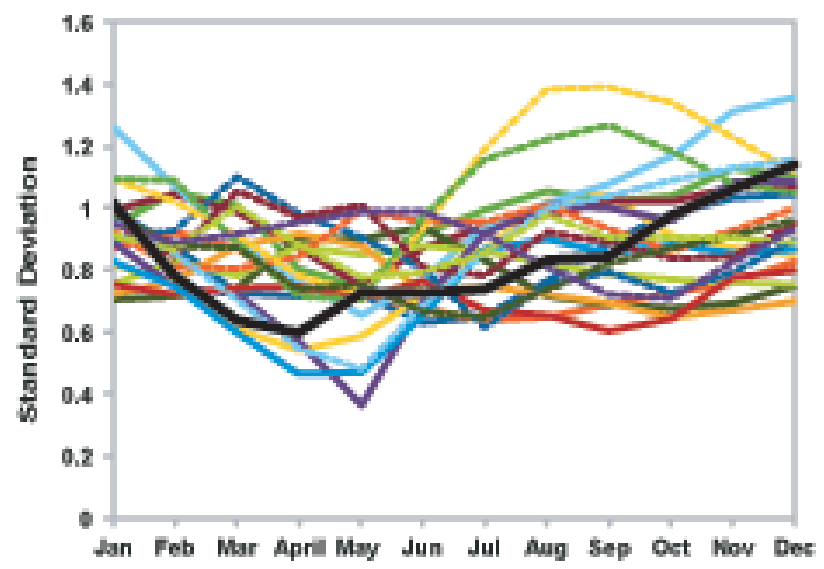

(c) IOBM

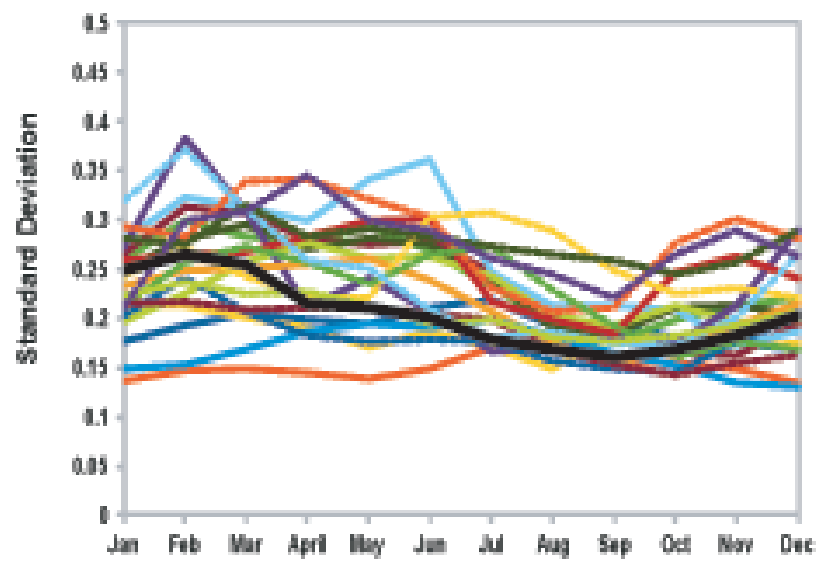

(b) EMI

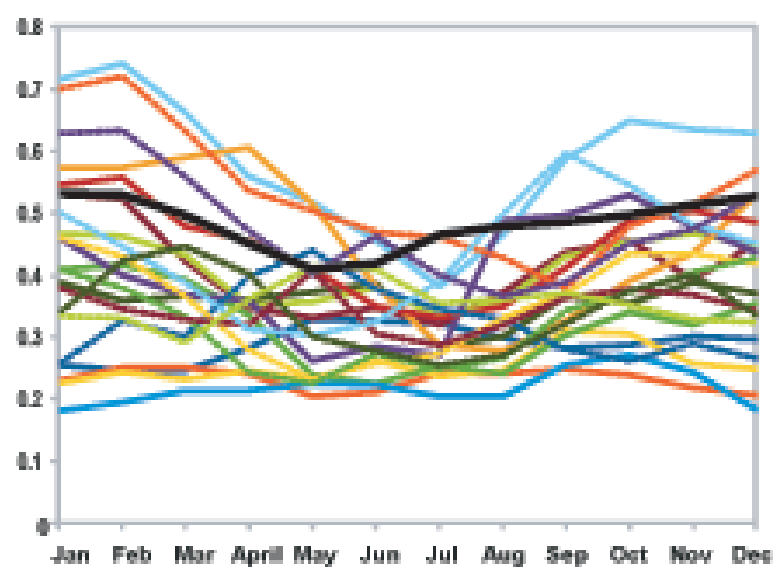

(d) IOD

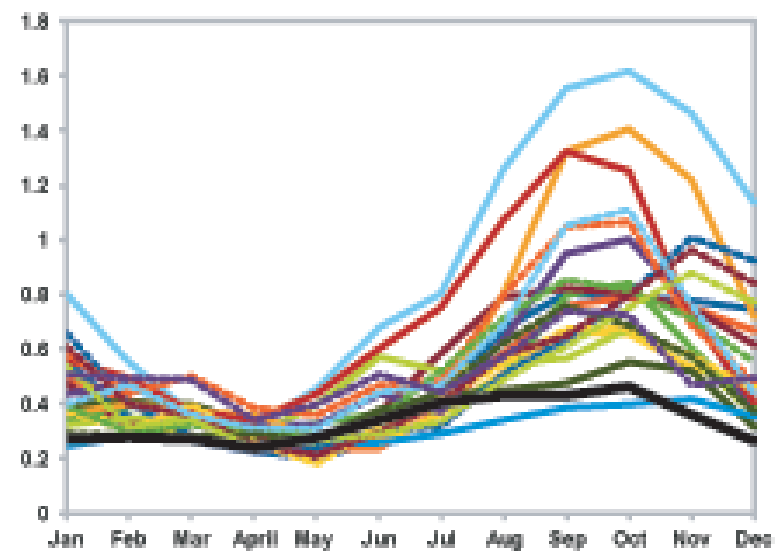

ACCESS1-0

ACCESS1-3

bec-esm1-1

CanesM2

CESM1-BOC

CESM1-CAUS

IPSL-CMSALR

IPSL-CMSA-MR

CNRM-CM5

CSIROMIS-60

MPI-ESM-MR

GISS-E2-H-OC

HadGEM2-CC

MPIESMLLR

NorEsh1aAE

NorEsM14

HadGEM2-ES

CNRM-CMS-2

HadCM 3

HadGEM2-AD

MPI-ESM-P

HadISST

Fig. 4 : Monthly Standard Deviation (SD) of a) Niño3, b) EMI, c) IOBM and d) IOD indices in CMIP5 $\mathrm{H}$ simulations. The black curve in each panel denotes the SD from HadISST dataset. 
(a) Nino3

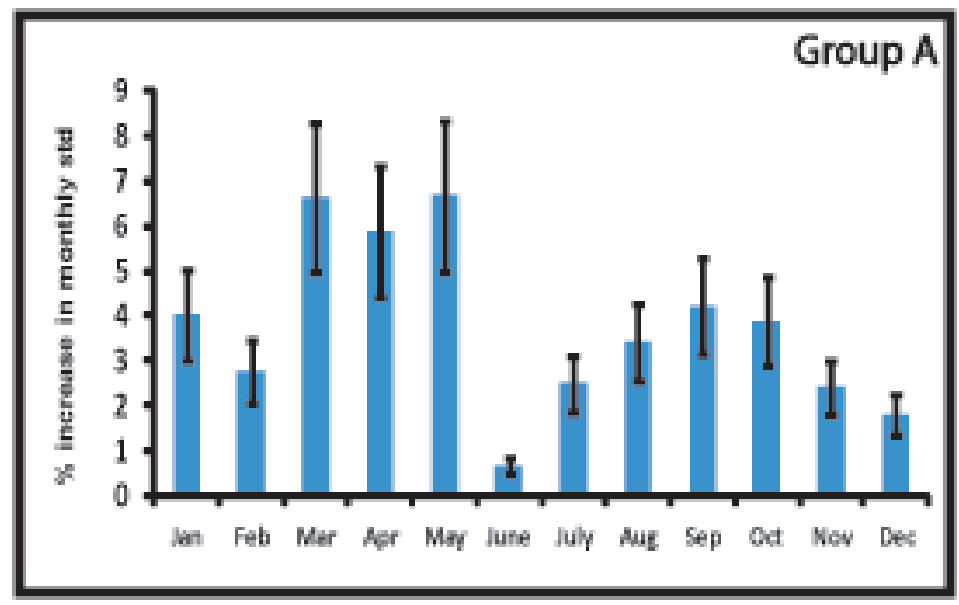

(c) EMI

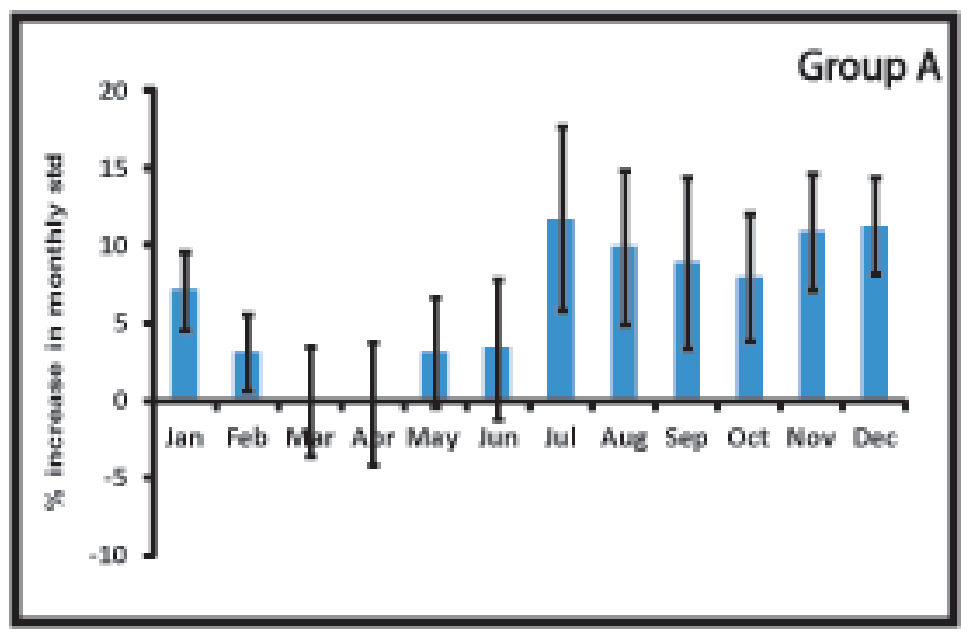

(b) Nino3

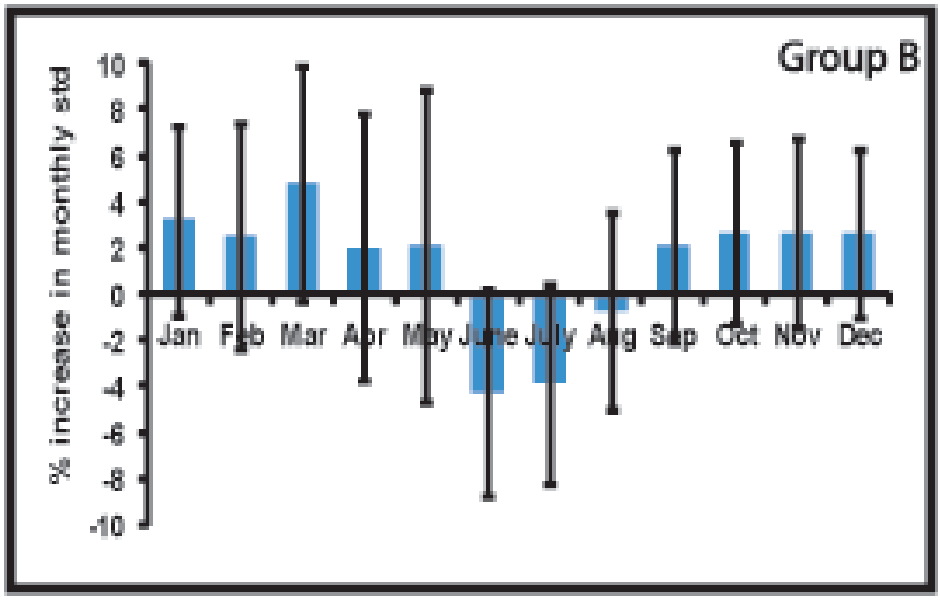

(d) EMI

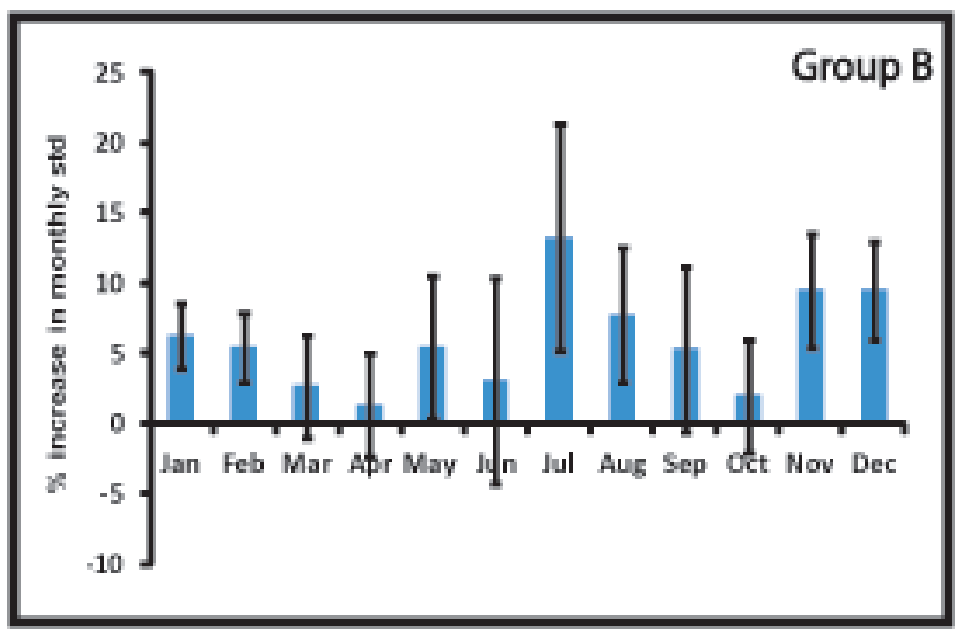

Fig. 5: Percent change in monthly SD of multi-model mean from $\mathrm{H}$ to RCP 8.5 of a) Nino3 for Group A, b) Nino3 for Group B, c) EMI for Group A, d) EMI for Group B. The error bars denote the SD of inter-model variability. 
(a) IOBM

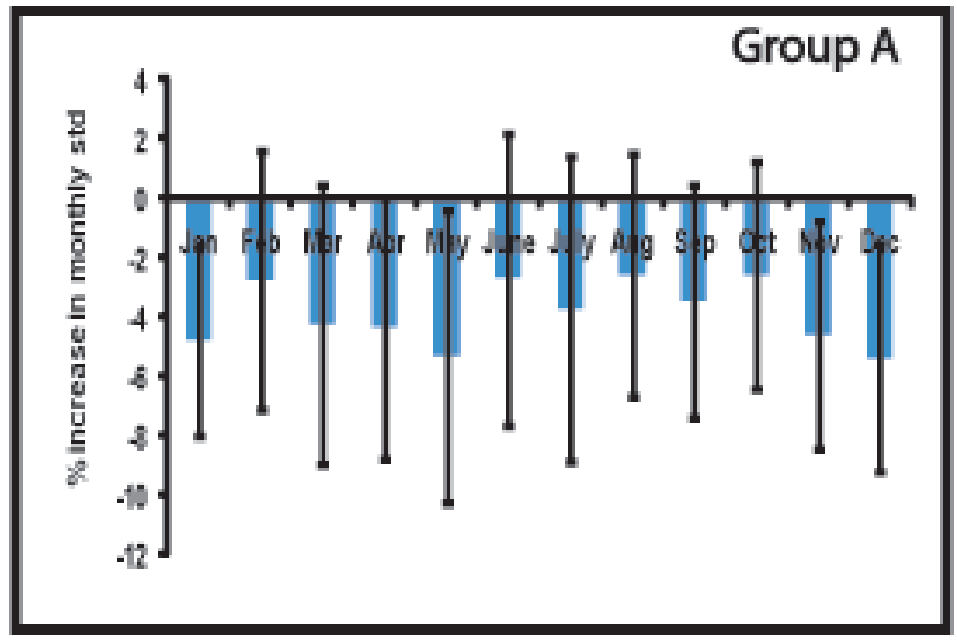

(c) IOD

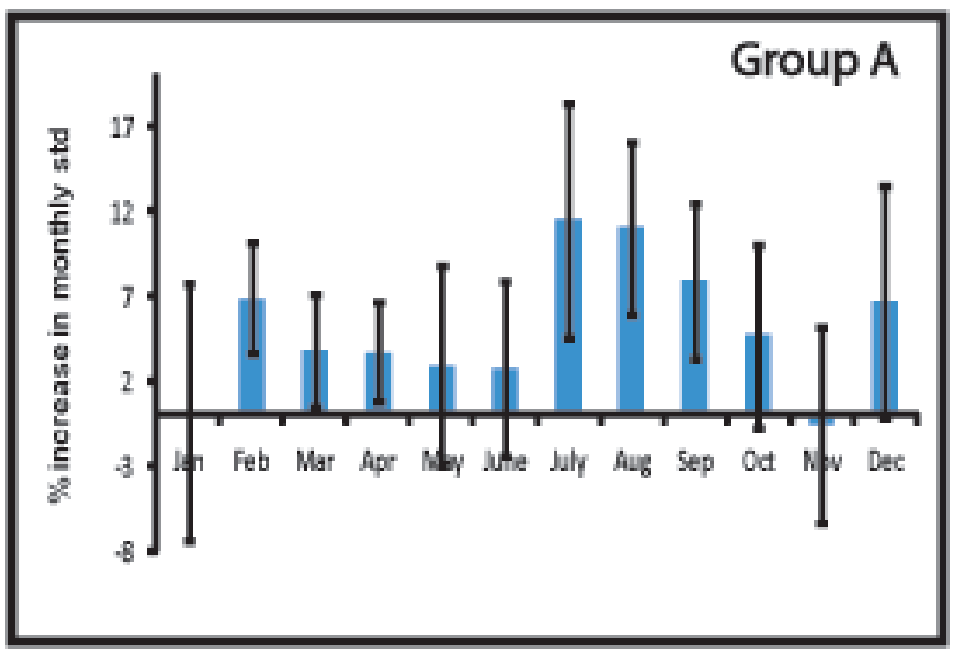

(b) IOBM

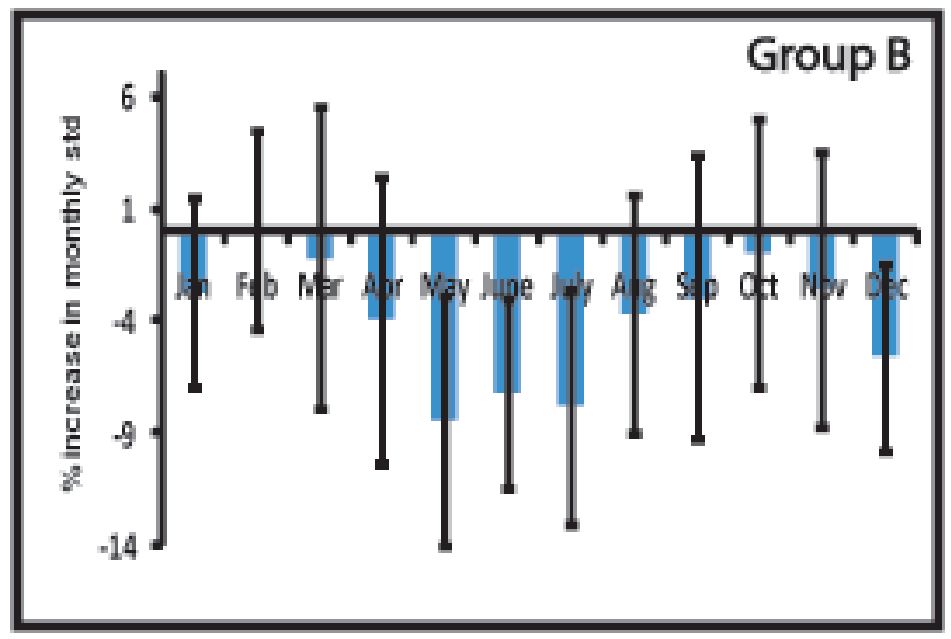

(d) IOD

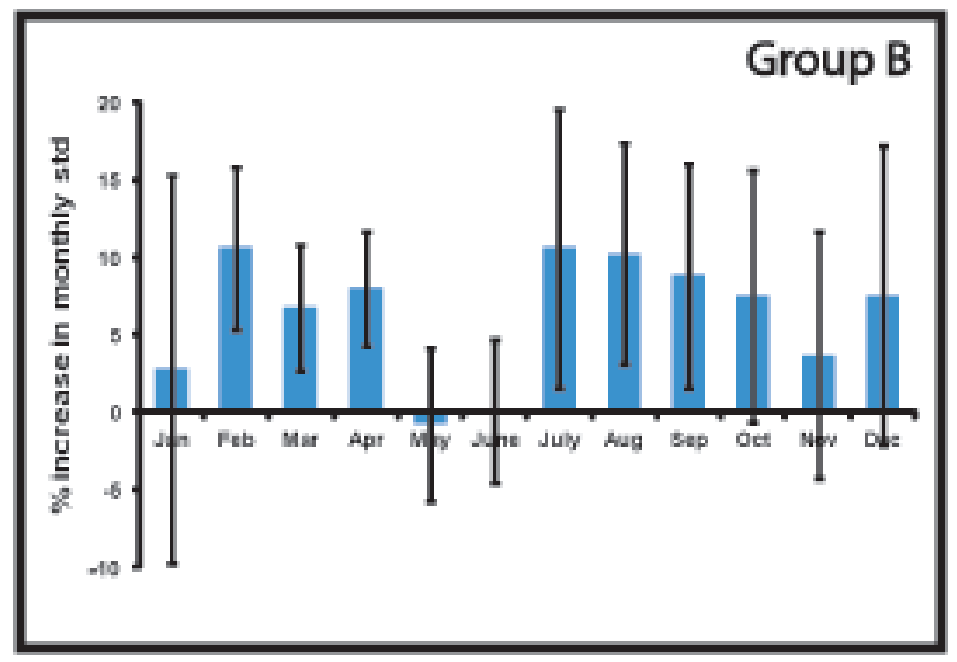

Fig. 6: Percent change in monthly SD of multi-model mean from $\mathrm{H}$ to RCP 8.5 of a) IOBM for Group A, b) IOBM for Group B, c) IOD for Group A, d) IOD for Group B. The error bars denote the SD of inter-model variability. 
(a)

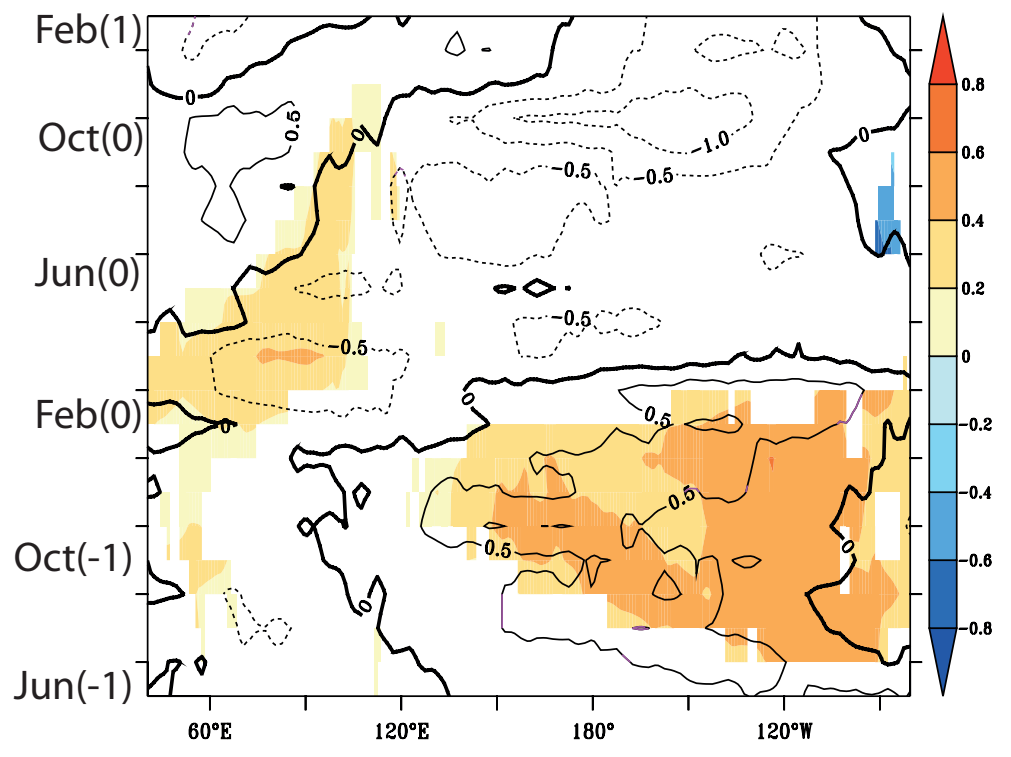

(c)

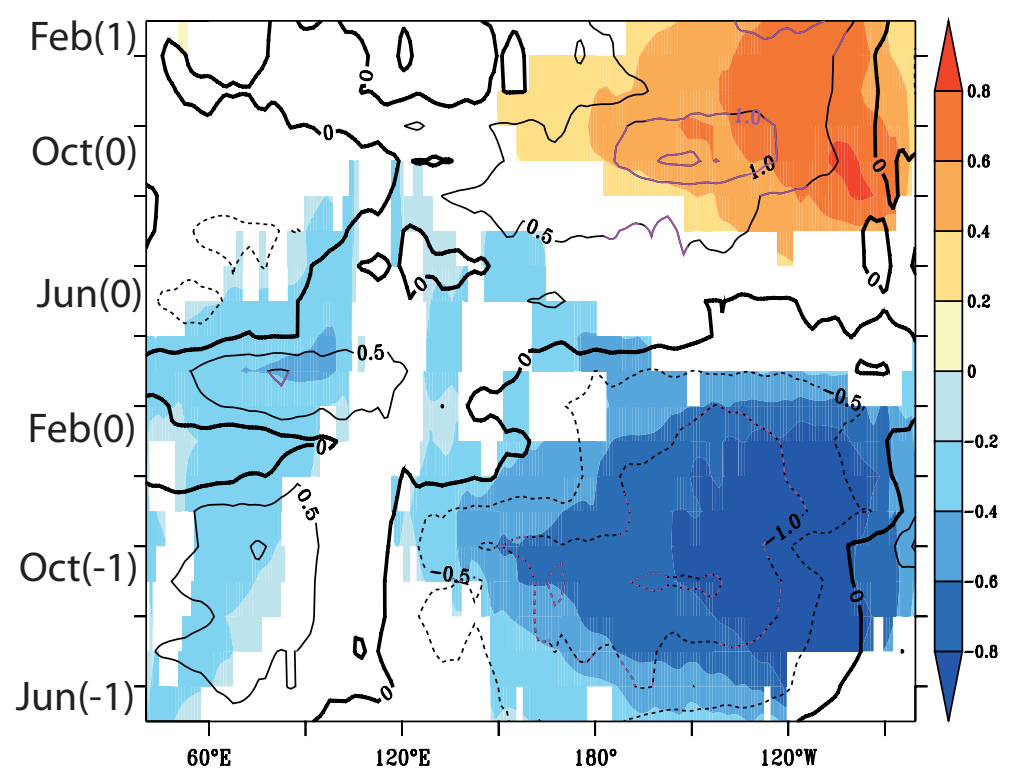

(b)

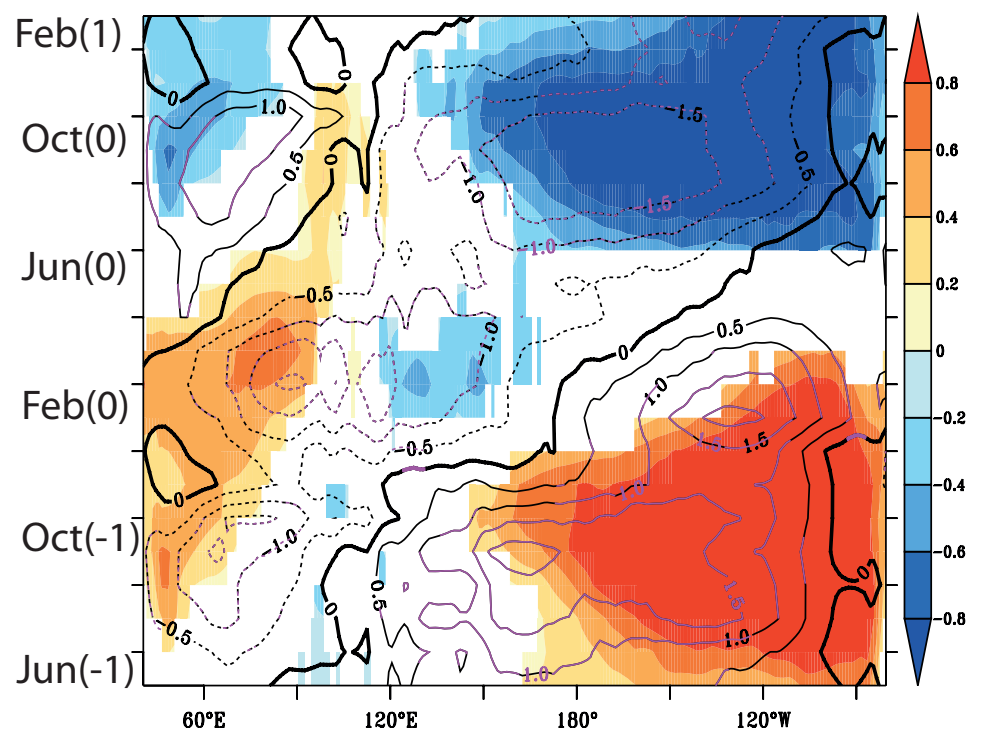

(d)

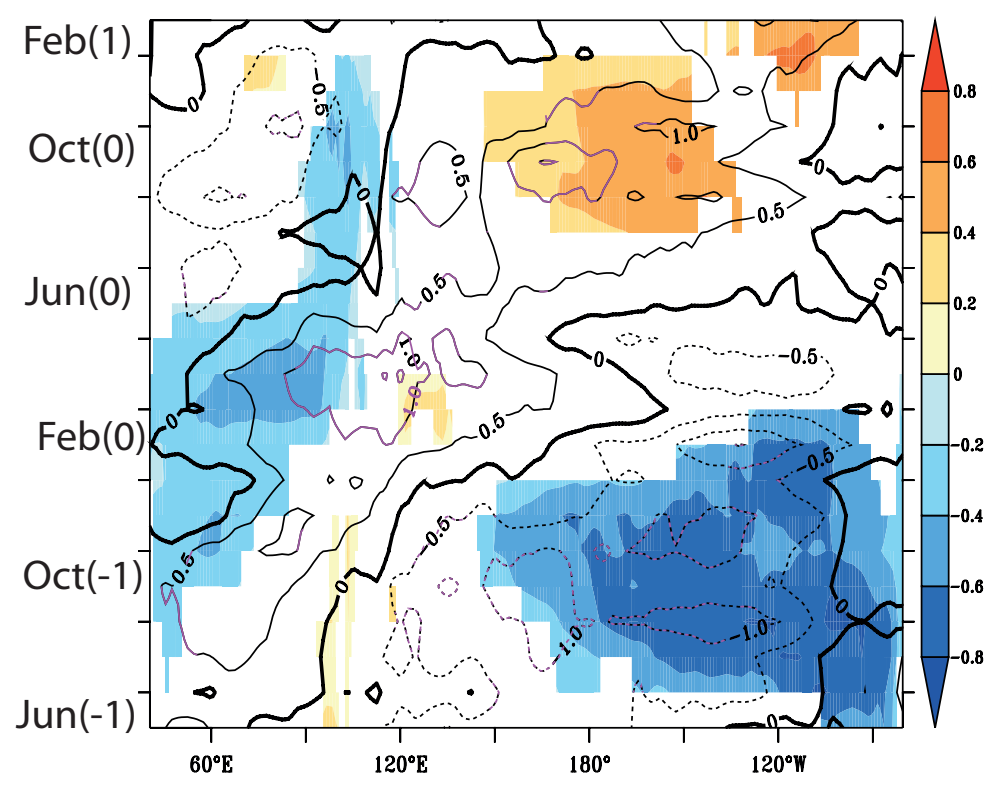

Fig. 8: $5^{\circ} \mathrm{S}-5^{\circ} \mathrm{N}$ averaged Hovmöller composite of SST (shading, ${ }^{\circ} \mathrm{C}$ ) and $850-\mathrm{hPa}$ zonal wind (contour, ms-1) anomalies in the TIP domain starting from June of year -1 (bottom) to February of year +1 (top) as simulated by the GISS-E2-H-CC model. Positive IOBM events in year 0 for (a) $\mathrm{H}$ and (b) RCP8.5 simulations. Negative IOBM events in year 0 for (c) H and (d) RCP8.5 simulations. Black bold contours represent zero $850-\mathrm{hPa}$ zonal wind anomalies and dashed contours indicate negative values (e.g. easterly850-hPa winds). Only significant SSTA above the $90 \%$ confidence level are shown (shading). Significant wind anomalies above the $90 \%$ confidence level are shown by purple contours. See text for more details. 
(a)

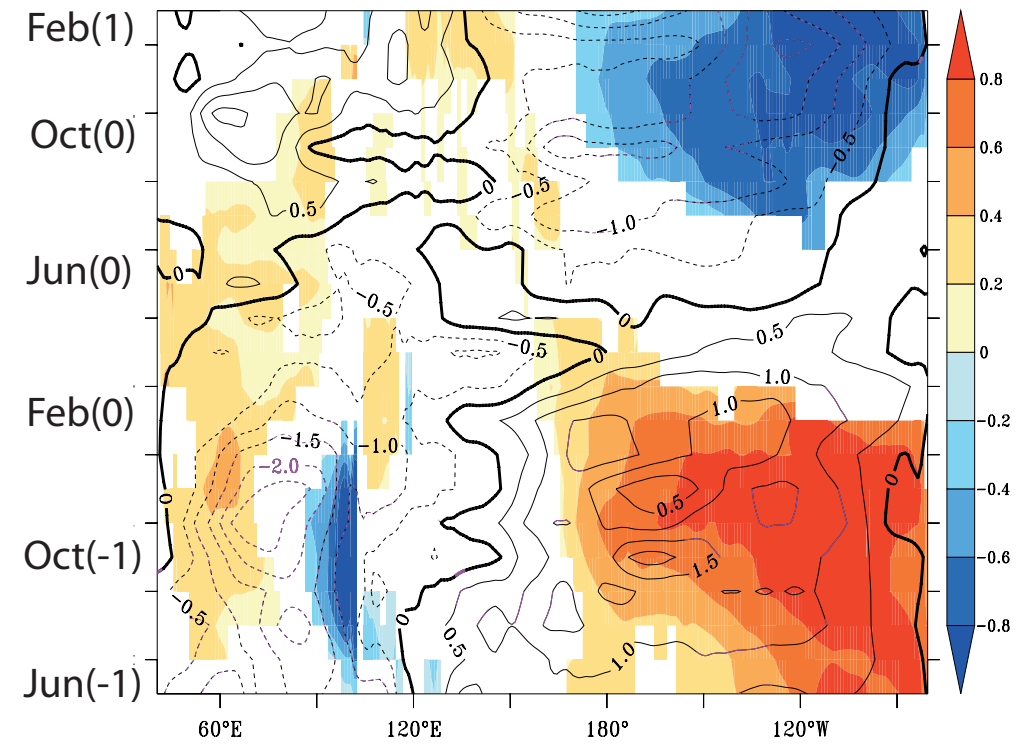

(c)

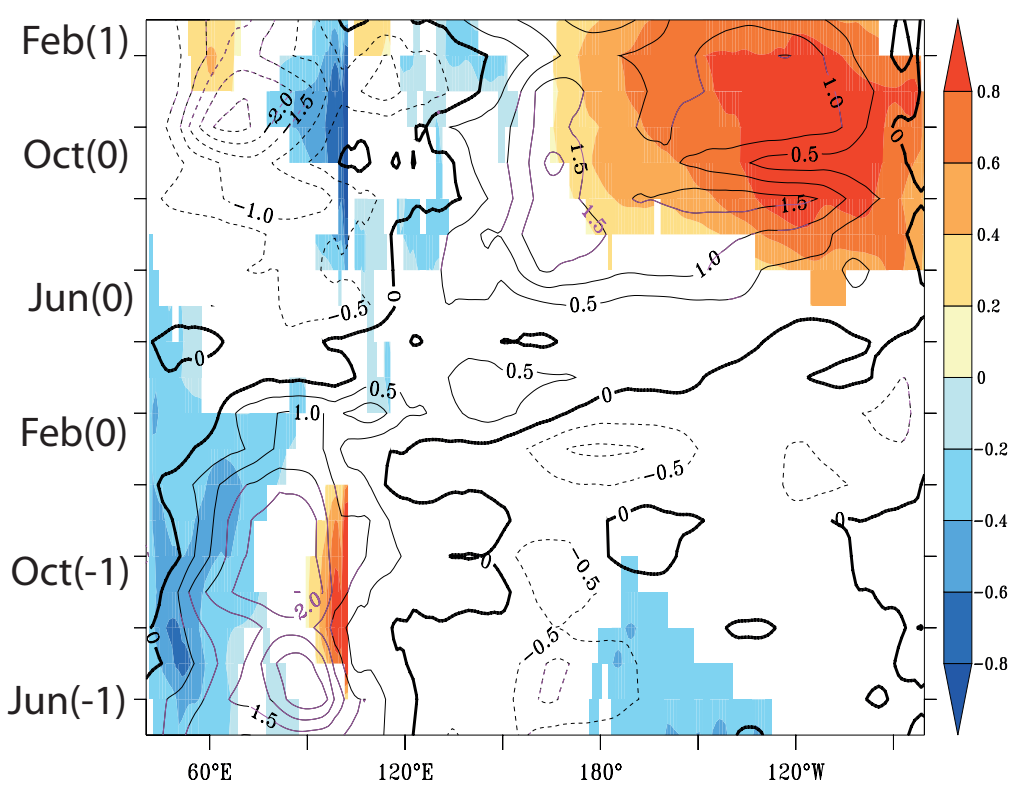

(b)

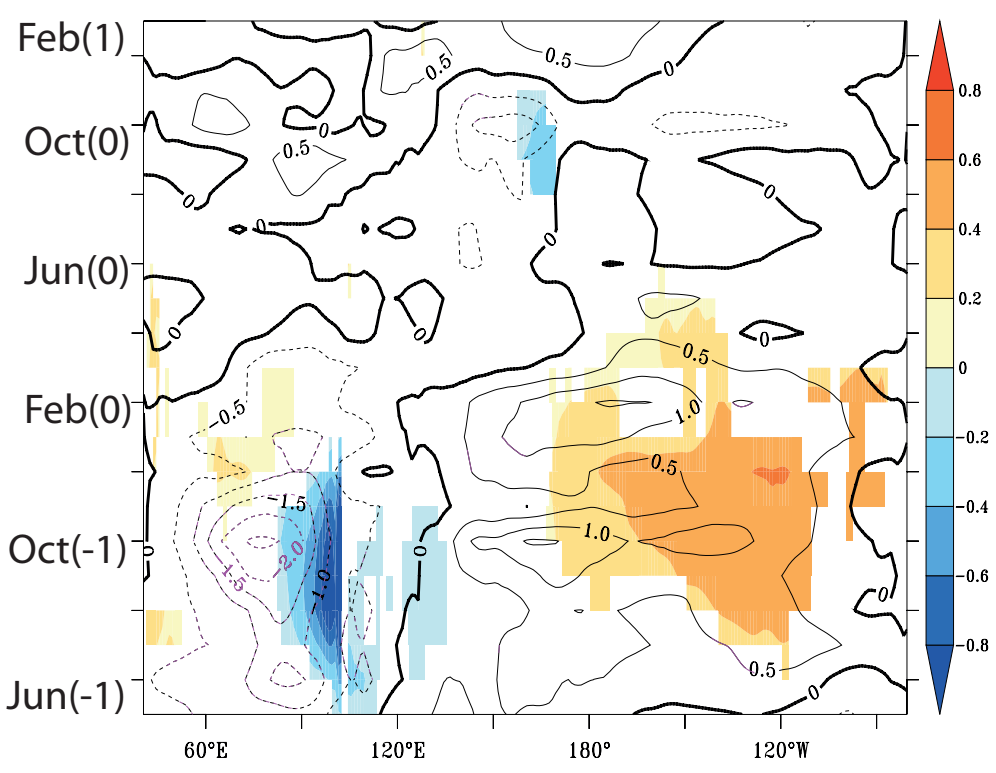

(d)

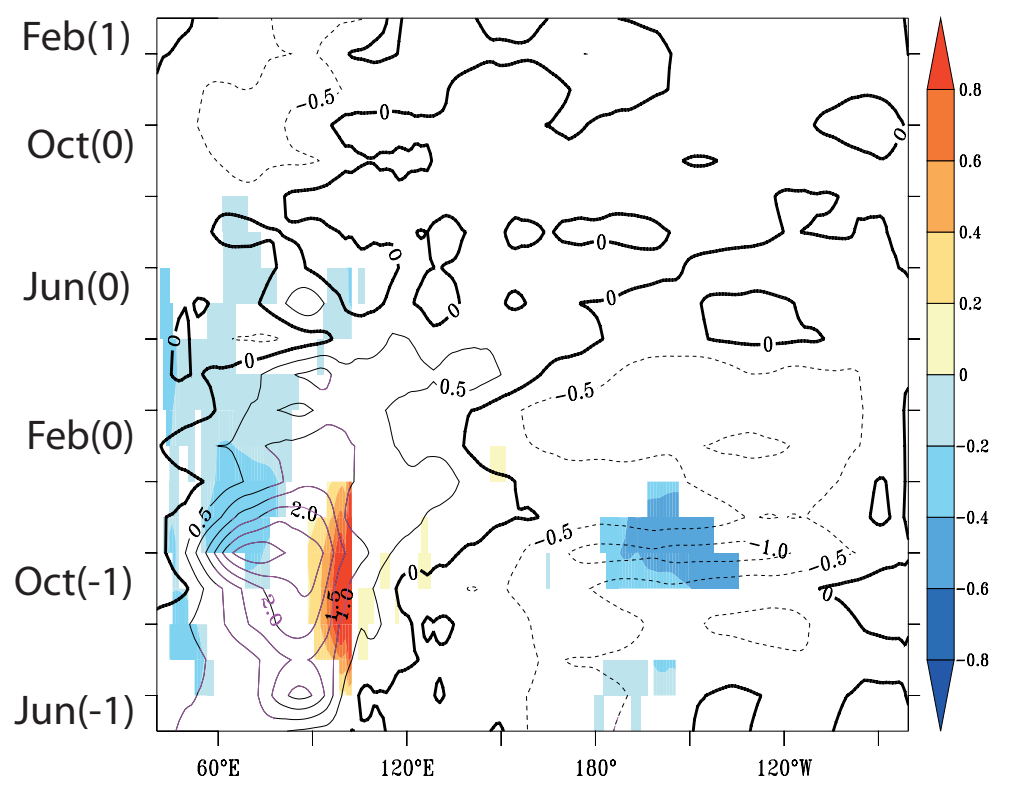

Fig. 9: $5^{\circ} \mathrm{S}-5^{\circ} \mathrm{N}$ averaged Hovmöller composite of SST ( shading, ${ }^{\circ} \mathrm{C}$ ) and $850-\mathrm{hPa}$ zonal wind (contour, ms-1) anomalies in the TIP domain starting from June of year -1 (bottom) to February of year +1 (top) as simulated by the ACCESS1-0 model. Positive IOD events in year -1 for (a) $\mathrm{H}$ and (b) RCP8.5 simulations. Negative IOD events in year -1 for (c) $\mathrm{H}$ and (d) RCP8.5simulations. Black bold contours represent zero $850 \mathrm{hPa}$ zonal wind anomalies and dashed contours indicate negative values (e.g. easterly 850 -hPa winds). Only s ignificant SSTA above the $90 \%$ confidence level are shown (shading). Significant wind anomalies above the $90 \%$ confidence level are shown by purple contours. See text for more details. 
Table 1:List of CMIP5 models along with their modeling groups and resolution.

\begin{tabular}{|c|c|c|}
\hline Model & Institution & $\begin{array}{l}\text { Resolution } \\
\text { (latitudex } \\
\text { longitude) }\end{array}$ \\
\hline ACCESS1.0 & $\begin{array}{l}\text { Commonwealth Scientific and Industrial } \\
\text { Research Organization (CSIRO) and Bureau of } \\
\text { Meteorology, (BOM), Australia }\end{array}$ & $300 \times 360$ \\
\hline ACCESS1.3 & $\begin{array}{l}\text { Commonwealth Scientific and Industrial } \\
\text { Research Organization (CSIRO) and Bureau of } \\
\text { Meteorology,(BOM), Australia }\end{array}$ & $300 \times 360$ \\
\hline BCC-CSM1-1 & $\begin{array}{l}\text { Beijing Climate Center, China Meteorological } \\
\text { Administration, China }\end{array}$ & $232 \times 360$ \\
\hline CCSM4 & $\begin{array}{l}\text { National Center for Atmospheric Research, } \\
\text { USA }\end{array}$ & $384 \times 320$ \\
\hline CanESM2 & $\begin{array}{l}\text { Canadian Centre for Climate Modeling and } \\
\text { Analysis, Canada }\end{array}$ & $192 \times 256$ \\
\hline CESM1-BGC & NSF-DOE-NCAR & $384 \times 320$ \\
\hline CESM1-CAM5 & NSF-DOE-NCAR & $384 \times 320$ \\
\hline $\begin{array}{l}\text { CESM1- } \\
\text { WACCM }\end{array}$ & NSF-DOE-NCAR & $384 \times 320$ \\
\hline CNRM-CM5 & $\begin{array}{l}\text { Centre National de RecherchesMeteoro- } \\
\text { logiques and Centre Europeen de Recherche et } \\
\text { Formation Avancees en CalculScientifique }\end{array}$ & $292 \times 362$ \\
\hline CNRM-CM5-2 & $\begin{array}{l}\text { Centre National de RecherchesMeteoro- } \\
\text { logiques and Centre Europeen de Recherche et } \\
\text { Formation Avancees en CalculScientifique }\end{array}$ & $292 \times 362$ \\
\hline CSIRO-Mk3.6.0 & $\begin{array}{l}\text { Commonwealth Scientific and Industrial } \\
\text { Research Organization in collaboration with the } \\
\text { Queensland Climate Change Centre of } \\
\text { Excellence, Australia }\end{array}$ & $189 \times 192$ \\
\hline EC-EARTH & & $292 \times 362$ \\
\hline GFDL-ESM2M & Geophysical Fluid Dynamics Laboratory, USA & $200 \times 360$ \\
\hline GISS-E2-H & NASA Goddard Institute for Space Studies, NY & $90 \times 144$ \\
\hline GISS-E2-H-CC & NASA Goddard Institute for Space Studies, NY & $90 \times 144$ \\
\hline GISS-E2-R & NASA Goddard Institute for Space Studies, NY & $90 \times 144$ \\
\hline GISS-E2-R-CC & NASA Goddard Institute for Space Studies, NY & $90 \times 144$ \\
\hline HadCM3 & Met Office Hadley Centre, UK & $144 \times 288$ \\
\hline
\end{tabular}




\begin{tabular}{|l|l|l|}
\hline HadGEM2-AO & $\begin{array}{l}\text { National Institute of Meteorological } \\
\text { Research/Korea Meteorological } \\
\text { Administration, South Korea }\end{array}$ & $216 \times 360$ \\
\hline HadGEM2-CC & Met Office Hadley Centre, UK & $216 \times 360$ \\
\hline HadGEM2-ES & Met Office Hadley Centre, UK & $216 \times 360$ \\
\hline INM-CM4 & Institute for Numerical Mathematics, Russia & $340 \times 360$ \\
\hline IPSL-CM5A-LR & Institute Pierre-Simon Laplace, France & $149 \times 182$ \\
\hline IPSL-CM5A-MR & Institute Pierre-Simon Laplace, France & $149 \times 182$ \\
\hline MIROC5 & $\begin{array}{l}\text { Atmosphere and Ocean Research Institute (The } \\
\text { University of Tokyo), National Institute for } \\
\text { Environmental Studies, and Japan Agency for } \\
\text { Marine-Earth Science and Technology, Japan }\end{array}$ & $224 \times 256$ \\
\hline MPI-ESM-LR & $\begin{array}{l}\text { Max Planck Institute for Meteorology (MPI-M), } \\
\text { Germany }\end{array}$ & $220 \times 256$ \\
\hline MPI-ESM-MR & $\begin{array}{l}\text { Max Planck Institute for Meteorology (MPI-M), } \\
\text { Germany }\end{array}$ & $404 \times 802$ \\
\hline MPI-ESM-P & $\begin{array}{l}\text { Max Planck Institute for Meteorology (MPI-M), } \\
\text { Germany }\end{array}$ & $220 \times 256$ \\
\hline MRI-CGCM3 & Meteorological Research Institute, Japan & $368 \times 360$ \\
\hline MRI-ESM1 & Meteorological Research Institute, Japan & $368 \times 360$ \\
\hline NorESM1-M & Norwegian Climate Centre, Norway & $384 \times 320$ \\
\hline NorESM1-ME & Norwegian Climate Centre, Norway & $384 \times 320$ \\
\hline & & \\
\hline & & \\
\hline
\end{tabular}


Table 2: Explained variances of the first three leading EOF modes using "raw" and detrended SSTA over three domains viz., TP, TIO and TIP for the 1958-2005 period.

\begin{tabular}{|c|c|c|c|c|c|c|}
\hline & \multicolumn{3}{|c|}{ Explained variance (\%) } & \multicolumn{3}{c|}{ Explained variance (\%) } \\
\hline & \multicolumn{3}{|c|}{ Raw data } & \multicolumn{3}{c|}{ Detrended data } \\
\hline & EOF1 & EOF2 & EOF3 & EOF1 & EOF2 & EOF3 \\
\hline TP & 41.8 & 10.3 & 8.0 & 43.5 & 10.8 & 4.7 \\
\hline TIO & 39.9 & 13.2 & 8.6 & 29.2 & 15.9 & 10.1 \\
\hline TIP & 37.9 & 9.7 & 8.8 & 39.4 & 9.6 & 2 \\
\hline
\end{tabular}


Table 3: List of CMIP5 models, ranked according to normalized RMSE values computed from the first 8 reference EOF modes estimated from detrended TIP SSTA in the HadISST dataset for the 1958-2005period. The normalized RMSE statistics for TP and TIO domains are also shown to assess the robustness of the ranking of the CMIP5 models with respect to the domain definition.

\begin{tabular}{|c|c|c|c|c|}
\hline Rank & TIP & TP & TIO & Model \\
\hline 1. & 0.06 & 0.07 & 0.62 & MPI-ESM-P \\
\hline 2. & 0.12 & 0.11 & 0.21 & HadGEM2-ES \\
\hline 3. & 0.12 & 0.13 & 0.2 & NorESM1-M \\
\hline 4. & 0.16 & 0.17 & 0.68 & CSIRO-Mk3-6-0 \\
\hline 5. & 0.16 & 0.16 & 0.24 & HadGEM2-AO \\
\hline 6. & 0.17 & 0.18 & 0.46 & CNRM-CM5-2 \\
\hline 7. & 0.18 & 0.18 & 0.41 & CanESM2 \\
\hline 8. & 0.18 & 0.18 & 0.92 & HadCM3 \\
\hline 9. & 0.19 & 0.19 & 0.33 & IPSL-CM5A-MR \\
\hline 10. & 0.20 & 0.16 & 0.64 & MPI-ESM-LR \\
\hline 11. & 0.22 & 0.24 & 0.32 & CESM1-BGC \\
\hline 12. & 0.25 & 0.26 & 0.32 & IPSL-CM5A-LR \\
\hline 13. & 0.25 & 0.27 & 0.49 & MPI-ESM-MR \\
\hline 14. & 0.25 & 0.26 & 0.39 & CNRM-CM5 \\
\hline 15. & 0.26 & 0.25 & 0.2 & ACCESS1-0 \\
\hline 16. & 0.29 & 0.29 & 0.19 & HadGEM2-CC \\
\hline 17. & 0.30 & 0.31 & 0.39 & NorESM1-ME \\
\hline 18. & 0.32 & 0.31 & 0.34 & ACCESS1-3 \\
\hline 19. & 0.40 & 0.4 & 0.93 & CESM1-CAM5 \\
\hline 20. & 0.46 & 0.45 & 0.36 & GISS-E2-H-CC \\
\hline 21. & 0.47 & 0.45 & 0.21 & BCC-CSM1-1 \\
\hline 22. & 0.59 & 0.58 & 0.3 & GISS-E2-H \\
\hline 23. & 0.59 & 0.59 & 0.72 & CESM1-WACCM \\
\hline 24. & 0.60 & 0.64 & 0.5 & CCSM4 \\
\hline 25. & 0.60 & 0.61 & 0.24 & EC-EARTH \\
\hline 26. & 0.63 & 0.63 & 0.27 & GISS-E2-R \\
\hline 27. & 0.66 & 0.66 & 0.39 & MRI-CGCM3 \\
\hline 28. & 0.66 & 0.67 & 0.33 & MRI-ESM-1 \\
\hline 29. & 0.69 & 0.71 & 0.2 & GISS-E2-R-CC \\
\hline 30. & 0.71 & 0.69 & 0.63 & INMCM4 \\
\hline 31. & 1.448 & 1.43 & 1.61 & GFDL-ESM-2M \\
\hline 32. & 1.579 & 1.51 & 1.7 & MIROC5 \\
\hline
\end{tabular}


Table 4:Classification of the CMIP5 models according to their ability to simulate the phase-locking of canonical ENSO events to the seasonal cycle, see text for details. Group A consists of all sixteen models, which have both H and RCP 8.5 simulations. The correlation coefficients between the monthly SD of Niño3 SST for each model and observations are computed and shown in the last column.The models with a positive correlation coefficient significant at $90 \%$ confidence level are shown in bold and are classified as Group B.

\begin{tabular}{|c|c|c|}
\hline Sr. No. & Group A & $\begin{array}{l}\text { Correlation between } \\
\text { Niño3 index of models and } \\
\text { observation }\end{array}$ \\
\hline 1. & NorESM1-M & 0.51 \\
\hline 2. & CSIRO-Mk3-6-0 & -0.78 \\
\hline 3. & CanESM2 & 0.62 \\
\hline 4. & IPSL-CM5A-MR & -0.8 \\
\hline 5. & MPI-ESM-LR & 0.36 \\
\hline 6. & CESM1-BGC & 0.64 \\
\hline 7. & IPSL-CM5A-LR & -0.61 \\
\hline 8. & MPI-ESM-MR & 0.18 \\
\hline 9. & CNRM-CM5 & 0.73 \\
\hline 10. & ACCESS1-0 & 0.89 \\
\hline 11. & HadGEM2-CC & -0.3 \\
\hline 12. & NorESM1-ME & 0.55 \\
\hline 13. & ACCESS1-3 & 0.2 \\
\hline 14. & CESM1-CAM5 & 0.9 \\
\hline 15. & GISS-E2-H-CC & 0.71 \\
\hline 16. & BCC-CSM1-1 & 0.57 \\
\hline
\end{tabular}


Table 5: Multi model "simultaneous" correlations between IOBM, IOD and Nino3 for H and RCP 8.5 simulations for all models in Groups A and B. The values in parenthesis denote the SD of inter-model correlation for the different pairs of climate indexes. Values in bold are statistically significant at the $90 \%$ confidence level according to a 2-tailed Student's t-test. Each index is computed during its peak season and for each couple of indexes, the first index is leading the second one. See text for more details.

\begin{tabular}{|c|r|r|r|r|r|r|}
\hline & \multicolumn{2}{|r|}{ IOD \& IOBM } & \multicolumn{2}{|r|}{ IOD \& Nino3 } & \multicolumn{2}{r|}{ Nino3 \& IOBM } \\
\hline & H & RCP 8.5 & H & RCP 8.5 & H & RCP 8.5 \\
\hline Observation & $\mathbf{0 . 4 7}$ & & $\mathbf{0 . 6 7}$ & & $\mathbf{0 . 8 1}$ & \\
\hline Group A & $\mathbf{0 . 4 1}$ & $\mathbf{0 . 4 3}(0.21)$ & $\mathbf{0 . 4 2}$ & $\mathbf{0 . 3 8}$ & $\mathbf{0 . 6 3}$ & $\mathbf{0 . 6 7}$ \\
& $(0.18)$ & & $(0.2)$ & $(0.25)$ & $(0.13)$ & $(0.12)$ \\
\hline Group B & $\mathbf{0 . 4 6}$ & $\mathbf{0 . 5 2}$ & $\mathbf{0 . 5 3}$ & $\mathbf{0 . 5 4}$ & $\mathbf{0 . 6 3}$ & $\mathbf{0 . 6 9}$ \\
& & & & & & $(0.14)$ \\
& $(0.16)$ & $(0.18)$ & $(0.16)$ & $(0.19)$ & $(0.12)$ \\
\hline
\end{tabular}


Table 6: Multi-model mean of lead correlations between IOD (year 0) and IOBM (year +1 ) during their peak season and Niño3 index in the following year (e.g. year +1 ) in $\mathrm{H}$ and RCP 8.5 simulations for both Groups A and B models. The values in parenthesis denote the SD of inter-model correlation for the different pairs of climate indexes. Values in bold are statistically significant at the $90 \%$ confidence level according to a 2-tailed Student's t-test.

\begin{tabular}{|c|c|c|c|c|}
\hline & Historical & RCP 8.5 & Historical & RCP 8.5 \\
\hline $\begin{array}{c}\text { Fix } \\
\text { Moving }\end{array}$ & $\begin{array}{c}\text { IOD } \\
\text { Niño3 }\end{array}$ & $\begin{array}{c}\text { IOD } \\
\text { Niño3 }\end{array}$ & $\begin{array}{c}\text { IOBM } \\
\text { Niño3 }\end{array}$ & $\begin{array}{c}\text { IOBM } \\
\text { Niño3 }\end{array}$ \\
\hline & IOD leads & IOD leads & IOBM leads & IOBM leads \\
\hline Observation & $\mathbf{- 0 . 3 9}$ & & -0.17 & \\
\hline Group A & $\mathbf{- 0 . 3 5}$ & $\mathbf{- 0 . 3 2}$ & -0.17 & $(0.22)$ \\
& $(0.16)$ & $(0.2)$ & $\mathbf{- 0 . 3 2}$ \\
& & $-\mathbf{0 . 3 5}$ & $\mathbf{- 0 . 3 2}$ & $(0.22)$ \\
\hline Group B & $\mathbf{- 0 . 4 1}$ & $(0.17)$ & $(0.09)$ & $(0.19)$ \\
& $(0.1)$ & & & \\
\hline
\end{tabular}


Table 7: Multi-model mean of coefficient of determination for multiple linear prediction of Niño3 SST in DJF of year+1 (e.g. D of year 0 and JF of year +1) using different predictors from observations, $\mathrm{H}$ and $\mathrm{RCP} 8.5$ simulations for both groups $\mathrm{A}$ and $\mathrm{B}$. The values in parenthesis denote the SD of inter-model coefficient of determination.

\begin{tabular}{|c|c|c|c|c|c|}
\hline \multirow[t]{2}{*}{$\operatorname{Nino3(1)}$} & \multicolumn{2}{|c|}{ Group A } & \multicolumn{2}{|c|}{ Group B } & \multirow[t]{2}{*}{ Observation } \\
\hline & Historical & RCP 8.5 & Historical & RCP 8.5 & \\
\hline $\operatorname{Nino3}(0)$ & $\begin{array}{c}0.06 \\
(0.09)\end{array}$ & $\begin{array}{l}0.05 \\
(0.1)\end{array}$ & $\begin{array}{l}0.09 \\
(0.1)\end{array}$ & $\begin{array}{c}0.09 \\
(0.12)\end{array}$ & 0.02 \\
\hline IOBM(0) & $\begin{array}{c}0.07 \\
(0.07)\end{array}$ & $\begin{array}{l}0.15 \\
(0.16)\end{array}$ & $\begin{array}{c}0.1 \\
(0.06)\end{array}$ & $\begin{array}{l}0.22 \\
(0.18)\end{array}$ & 0.03 \\
\hline $\operatorname{IOD}(-1)$ & $\begin{array}{c}0.14 \\
(0.08)\end{array}$ & $\begin{array}{c}0.14 \\
(0.12)\end{array}$ & $\begin{array}{c}0.17 \\
(0.08)\end{array}$ & $\begin{array}{c}0.15 \\
(0.12)\end{array}$ & 0.14 \\
\hline $\begin{array}{l}\operatorname{Nino3}(0), \\
\operatorname{IOBM}(0)\end{array}$ & $\begin{array}{c}0.11 \\
(0.09)\end{array}$ & $\begin{array}{c}0.18 \\
(0.17)\end{array}$ & $\begin{array}{c}0.16 \\
(0.08)\end{array}$ & $\begin{array}{c}0.26 \\
(0.18)\end{array}$ & 0.03 \\
\hline Nino3(0), IOD(-1) & $\begin{array}{c}0.18 \\
(0.08)\end{array}$ & $\begin{array}{c}0.18 \\
(0.13)\end{array}$ & $\begin{array}{c}0.22 \\
(0.07)\end{array}$ & $\begin{array}{c}0.19 \\
(0.14)\end{array}$ & 0.15 \\
\hline $\operatorname{IOBM}(0), \operatorname{IOD}(-1)$ & $\begin{array}{c}0.18 \\
(0.08)\end{array}$ & $\begin{array}{c}0.20 \\
(0.16)\end{array}$ & $\begin{array}{c}0.2 \\
(0.07)\end{array}$ & $\begin{array}{l}0.25 \\
(0.18)\end{array}$ & 0.14 \\
\hline $\begin{array}{l}\text { Nino3(0), IOD(-1), } \\
\text { IOBM(0) }\end{array}$ & $\begin{array}{c}0.22 \\
(0.08)\end{array}$ & $\begin{array}{c}0.25 \\
(0.17)\end{array}$ & $\begin{array}{c}0.26 \\
(0.06)\end{array}$ & $\begin{array}{c}0.29 \\
(0.18)\end{array}$ & 0.17 \\
\hline
\end{tabular}


Table 8: Multi-model mean of adjusted coefficient of determination (adjusted $\mathrm{R}^{2}$ ) for multiple linear prediction of Niño3 SST in DJF of year +1 (e.g. D of year 0 and JF of year +1)using different predictors from observations, $\mathrm{H}$ and RCP 8.5 simulations for both groups A and B. The values in parenthesis denote the SD of inter-model adjusted coefficient of determination.

\begin{tabular}{|r|r|r|r|r|r|}
\hline & \multicolumn{2}{|c|}{ Group A } & \multicolumn{2}{c|}{ Group B } & Observation \\
\cline { 2 - 6 } & Historical & RCP 8.5 & Historical & RCP 8.5 & \\
\hline Nino3 (0) & 0.04 & 0.04 & 0.07 & 0.07 & 0.003 \\
& $(0.09)$ & $(0.1)$ & $(0.1)$ & $(0.12)$ & \\
\hline IOBM(0) & 0.05 & 0.13 & 0.08 & 0.2 & 0.01 \\
& $(0.07)$ & $(0.17)$ & $(0.07)$ & $(0.18)$ & 0.12 \\
\hline IOD(-1) & 0.12 & 0.12 & 0.15 & 0.13 & -0.01 \\
\hline Nino3(0), IOBM(0) & $(0.09)$ & $(0.12)$ & $(0.08)$ & $(0.12)$ & 0.11 \\
& 0.07 & 0.14 & 0.12 & 0.23 & $(0.18)$ \\
\hline Nino3(0), IOD(-1) & $(0.09)$ & $(0.17)$ & $(0.09)$ & 0.15 & 0.1 \\
& 0.14 & 0.14 & 0.19 & $(0.15)$ & \\
\hline Nino3(0), IOD(-1), & $(0.09)$ & $(0.14)$ & $(0.07)$ & 0.21 & $(0.19)$ \\
\hline IOBM(0) & 0.14 & 0.17 & 0.17 & 0.24 & $(0.2)$ \\
\hline
\end{tabular}


Figure S1

\section{Click here to access/download \\ Electronic Supplementary Material FigS1.pdf}

